Research Article

\title{
Comprehensive Evaluation of GPM-IMERG, CMORPH, and TMPA Precipitation Products with Gauged Rainfall over Mainland China
}

\author{
Guanghua Wei $\mathbb{D}^{1,2,3}$ Haishen Lü $\mathbb{D}^{1,3}$ Wade T. Crow ${ }^{1}{ }^{4},{ }^{4}$ Yonghua Zhu, ${ }^{1,3}$ \\ Jianqun Wang $\mathbb{D}^{1,3}$ and Jianbin $\mathrm{Su}^{1,3}$ \\ ${ }^{1}$ State Key Laboratory of Hydrology-Water Resources and Hydraulic Engineering, \\ National Cooperative Innovation Center for Water Safety \& Hydro-Science, College of Hydrology and Water Resources, \\ Hohai University, Nanjing 210098, China \\ ${ }^{2}$ School of Science, Jinling Institute of Technology, Nanjing 211169, China \\ ${ }^{3}$ Joint International Research Laboratory of Global Change and Water Cycle, Hohai University, Nanjing 210098, China \\ ${ }^{4}$ USDA-ARS Hydrology and Remote Sensing Laboratory, Bldg. 007, Rm. 104, BARC, West Beltsville, MD 20705-2350, USA \\ Correspondence should be addressed to Haishen Lü; haishenlu@foxmail.com and Wade T. Crow; wade.crow@ars.usda.gov
}

Received 28 June 2018; Accepted 25 September 2018; Published 4 December 2018

Academic Editor: Anthony R. Lupo

Copyright (c) 2018 Guanghua Wei et al. This is an open access article distributed under the Creative Commons Attribution License, which permits unrestricted use, distribution, and reproduction in any medium, provided the original work is properly cited.

\begin{abstract}
The comprehensive assessment of the Integrated Multi-satellitE Retrievals for the Global Precipitation Measurement (IMERG) V05B is important for benchmarking the product's continued improvement and future development. The performance of IMERG V05B precipitation products was systematically evaluated using 542 precipitation gauges at multiple spatiotemporal scales from March 2014 to February 2017 over China. Moreover, IMERG V05B was compared with IMERG V04A, the Tropical Rainfall Measuring Mission (TRMM) 3B42, and the Climate Prediction Center Morphing technique (CMORPH)-CRT in this study. Categorical verification techniques and statistical methods are used to quantify their performance. Results illustrate the following. (1) Except for IMERG V04A's severe underestimation over the Tibetan Plateau (TP) and Xinjiang (XJ) with high negative relative biases (RBs) and CMORPH-CRT's overestimation over XJ with high positive RB, the four satellite-based precipitation products generally capture the same spatial patterns of precipitation over China. (2) At the annual scale over China, the IMERG products do not show an advantage over its predecessor (TRMM 3B42) in terms of RMSEs, RRMSEs, and Rs; meanwhile, the performance of IMERG products is worse than TRMM 3B42 in spring and summer according to the RMSE, RRMSE, and $R$ metrics. Between the two IMERG products, IMERG V05B shows the anticipated improvement (over IMERG V04A) with a decrease in RMSE from 0.4496 to $0.4097 \mathrm{~mm} /$ day, a decrease of RRMSE from $16.95 \%$ to $15.44 \%$, and an increase of $R$ from 0.9689 to 0.9759 during the whole study period. Similar results are obtained at the seasonal scale. Among the four satellite products, CMORPH-CRT shows the worst seasonal performance with the highest RMSE $(0.6247 \mathrm{~mm} /$ day), RRMSE $(23.55 \%)$, and lowest $R(0.9343)$ over China. (3) Over XJ and TP, IMERG V05B clearly improves the strong underestimation of precipitation in IMERG V04A with the RBs of 5.2\% vs. $-21.8 \%$ over XJ, and $2.78 \%$ vs. $-46 \%$ over TP. Results at the annual scale are similar to those obtained at the seasonal scale, except for summer results over XJ. While, over the remaining subregions, the two IMERG products have a close performance; meanwhile, IMERG V04A slightly improves IMERG V05B's overestimation according to RBs (except for HN) at the annual scale. However, all four products are unreliable over XJ at both an annual and seasonal scale. (4) Across all products, TRMM 3B42 best reproduces the probability density function (PDF) of daily precipitation intensity. (5) According to the categorical verification technique in this study, both IMERG products yield better results for the detection of precipitation events on the basis of probability of detection (POD) and critical success index (CSI) categorical evaluations compared to TRMM 3B42 and CMORPHCRT over China and across most of the subregions. However, all four products have room for further improvement, especially in high-latitude and dry climate regions. These findings provide valuable feedback for both IMERG algorithm developers and data set users.
\end{abstract}




\section{Introduction}

Precipitation is a crucial component of the Earth's water and energy cycles. Reliable and accurate precipitation information plays an important role in hydrology, climatology, and water resource management [1-11]. Rain gauge networks may provide relatively accurate precipitation measurements but with an uneven distribution of stations and limited spatial representativeness [12]. Likewise, groundbased weather radars provide precipitation estimates at relatively high spatiotemporal resolution, but with limited utility in mountainous and cold regions [4, 13]. Recently, global scale precipitation estimates have become feasible through the development of satellite remote sensing techniques, and a series of satellite-based precipitation products (CMORPH [14], the TRMM Multi-satellite Precipitation Analysis (TMPA) [15], and IMERG [16]) have been developed and released.

The CMORPH technique integrates direct microwavebased retrievals of precipitation rate with observations of cloud top motion dynamics derived from infrared (IR) data to estimate high-resolution $\left(0.25^{\circ} / 8 \mathrm{~km}, 3 \mathrm{~h} / 0.5 \mathrm{~h}\right)$ global precipitation rates $\left(60^{\circ} \mathrm{N}-60^{\circ} \mathrm{S}\right)$. Many previous studies have evaluated the performance of CMORPH products [14, 17-21]. These efforts are essential to improve retrieval algorithms and to benefit satellite sensors development.

Since the launch of the TRMM satellite on 27 November 1997, TRMM-based satellite precipitation products have undergone a series of major revisions and widely used in hydrological applications [22-25]. After over 17 years of fruitful data gathering, the spacecraft was turned off and reentered the Earth's atmosphere on June 15, 2015. TMPA products, which combine remote sensing data from various passive microwave (PMW) and infrared (IR) sensors with gauge accumulation corrections based on the Global Precipitation Climatology Center (GPCC) monthly gauge analysis, aim to provide the global precipitation estimates from $50^{\circ} \mathrm{N}$ to $50^{\circ} \mathrm{S}$ at the TRMM-era. TMPA products have been widely examined and were proved to obtain a splendid success [26-29].

On 27 February 2014, the American National Aeronautics and Space Administration (NASA) and the Japan Aerospace Exploration Agency (JAXA) launched the Global Precipitation Measurement (GPM) Core Observatory satellite. The GPM mission relies on an international network of satellites to provide higher spatiotemporal resolution $\left(0.1^{\circ}, 30 \mathrm{~min}\right)$ global precipitation estimates $\left(60^{\circ} \mathrm{N}-60^{\circ} \mathrm{S}\right.$ at present and to be expanded to $90^{\circ} \mathrm{N}-90^{\circ} \mathrm{S}$ in future releases) than current TMPA products. IMERG is the Level 3 multisatellite precipitation algorithm of GPM, which combines sporadic precipitation rate estimates acquired from a constellation of microwave sensors, (relatively) continuous IR-based observations from geosynchronous satellites, and gridded monthly gauge precipitation data. Being a continuation of the successful TRMM mission, the GPM Microwave Imager (GMI) and the Dual-frequency Precipitation Radar (DPR) are an extension of TRMM's sensors. Relative to the TRMM precipitation radar, the DPR is more sensitive to light rainfall and snowfall.
The preliminary comparison was conducted between IMERG V03D and TMPA by Huffman et al. [30]. Results found that the two products are comparable over land. The IMERG products have been released recently, more comprehensive evaluations are still essential to better understand error characteristics of IMERG products. Some initial evaluations have been conducted over the world, such as India [31, 32], Singapore [33], Malaysia [34], a data-sparse mountainous watershed in Myanmar [35], Mekong river basin in Southeast Asia [36], and China [4, 13, 37-39]. These studies revealed that the performance of IMERG precipitation products varies from place to place. For example, IMERG V04A severely underestimates precipitation over the Tibetan Plateau cold region and the arid Xinjiang region in China [13], while IMERG V04A shows good performance over Singapore [33]. Therefore, a critical evaluation of satellite-based precipitation products is vital to understand their capability in a specific region before any application.

The algorithm for IMERG was updated to version 05 on 13 November 2017 [40]. Hereinafter, this new IMERG version is referred to as "IMERG V05B." A critical evaluation of IMERG V05B precipitation data is therefore required. With its large land area, complex topography, and diverse climate, China provides an important testbed for evaluating the quality of new remote sensing precipitation products. The eastern and northern parts of China are characterized by flat plains. The southeastern parts of China mainly consist of hilly regions. Deserts dominate the northwestern China, and high altitude mountain areas are distributed in the southwestern Chinese plateaus. Monsoon wind strongly influences seasonal climate variability. The precipitation regime of China is primarily influenced by the southwest and southeast monsoons originating from the Indian and Pacific Oceans, respectively [41]. The accuracy of precipitation estimation using satellites is highly influenced both by topography and climate. Our goal is to derive new insight into IMERG's error characteristics and provide useful evaluation information for both IMERG algorithms developers and data users.

\section{Study Areas, Datasets, and Methodology}

2.1. Study Areas. With a size of 9.6 million $\mathrm{km}^{2}$ and located between $73^{\circ}$ and $135^{\circ} \mathrm{E}$ and $18^{\circ}$ and $53^{\circ} \mathrm{N}$, China is characterized by complex topography with considerable variation and diverse climates. The study domain includes all of China with the exception of the South China Sea region (see Figure 1). Precipitation distribution of the southern and eastern parts of China is influenced by the Asian monsoon. In general, annual precipitation gradually increases from the northwest to southeast due to the Asian monsoon and complex terrain. Besides, given China's geographical location, the mainland China can be divided into four major climate districts including the subtropical monsoon climate (SMC), the monsoon climate of medium latitudes (MCML), the plateau climate, and the temperate continental monsoon climate (TCMC). The SMC covers the southeastern China characterized by the high precipitation. The spatial heterogeneity of precipitation over this region is also very high. Hence, for 


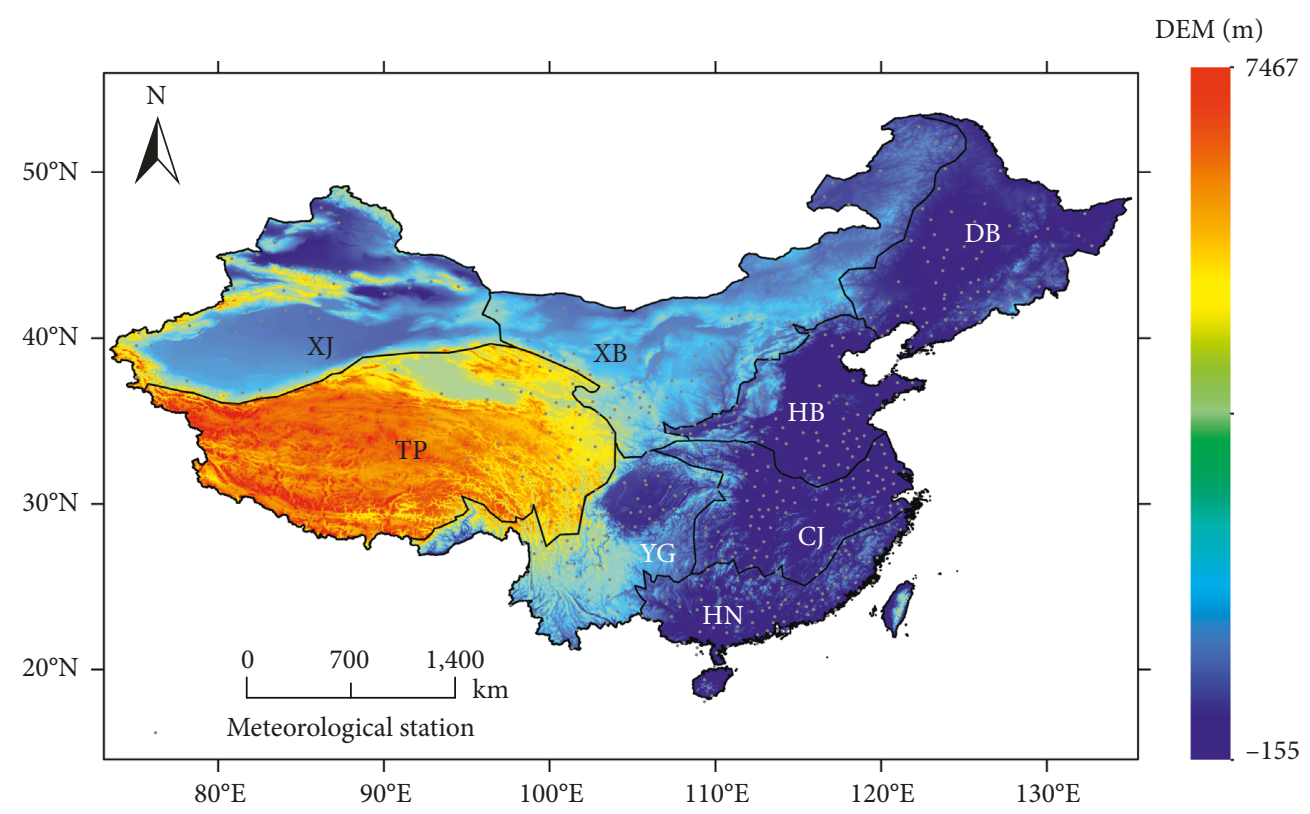

FIgURE 1: Study area, our eight subregions of interest: the Xinjiang region (XJ), the Qinghai-Tibetan Plateau (TP), Northwest China (XB), the southwest Yungui Plateau (YG), Northeastern China (DB), Northern China (HB), the plain region of Yangtze River (CJ), and Southeastern China $(\mathrm{HN})$, and the spatial distribution of meteorological stations within Mainland China.

further analysis, it has been divided into three subregions (the Southeastern China (HN) region, the Changjiang (CJ) River Plain region and the southwest Yungui Plateau (YG) region) based on the spatial distribution of average annual precipitation and the distribution of mountain. These three subregions are all characterized by hot and wet summers and mild and dry winters. The Northeastern China (DB) region and the Northern China $(\mathrm{HB})$ region are controlled by the MCML and belong to semihumid zone. However, although they both have hot-wet summers and cold-dry winters, the DB is characterized by the high latitude and the ice or snow cover in winter. The Xinjiang (XJ) region regarded as the arid region and the Northwestern China (XB) region known as the semiarid region are dominated by the TCMC. The QinghaiTibet Plateau (TP) cold region with an average elevation about $4500 \mathrm{~m}$ and complex terrain belongs to the plateau climate. All the eight subregions are shown in Figure 1. For more detailed information regarding the subregions, the readers can refer to the related studies $[11,13,21,37,38,42]$.

2.2. Gauge Precipitation Observations. The daily precipitation datasets of 542 separate automatic meteorological stations were provided and calibrated by CMA (the China Meteorological Administration). The spatial distribution of all meteorological stations is shown in Figure 1. These gauges were chosen for they contain no missing values between 12 March 2014 and 28 February 2017. The rain gauges which are sensitive to both liquid and solid precipitation monitor the measurements of precipitation 24 times every day. Daily precipitation was defined as accumulated precipitation depth over $24 \mathrm{~h}$ starting at $8 \mathrm{pm}$ local time. The National Meteorological Information Center (NMIC) performed the strict quality control check in three levels including the removal of questionable data, extreme value masking, and internal consistency checks [18, 43]. In this study, ground-based product datasets of the entire study period were downloaded from http://data.cma.cn/.

Many satellite-based precipitation estimates integrate the GPCC precipitation gauge data to calibrate their products. To avoid misleading results, the reference precipitation dataset used for the assessment of any satellite-based precipitation estimates should be independent from the GPCC product. Therefore, in this study, over Mainland China, rain stations used to construct the GPCC product have been explicitly excluded from reference gauges used for validation. As a result, our reference gauges (542 gauges) can be considered fully independent of gauge-adjusted satellite-based precipitation estimates such as the IMERG and TRMM 3B42 products.

\subsection{Satellite-Based Precipitation Datasets}

2.3.1. CMORPH-CRT. The CMORPH products are generated by the NOAA (National Oceanic and Atmospheric Administration) Climate Prediction Center's MORPHing technique. Recently, the NOAA Climate Prediction Center (CPC) reprocessed the CMORPH products. The original CMORPH version is called Version 0.x, and the reprocessed CMORPH version is called Version 1.0. The Version 1.0 products contain three individual rainfall products: (i) RAW (CMORPH-RAW), (ii) a bias-corrected product (CMORPH-CRT) and (iii) a gauge-satellite blended product (CMORPH-BLD). The CMORPH-RAW product is a satellite-only precipitation product based on PMW data with (high-temporal-resolution) IR imagery used to interpolate between successive PMW-derived rainfall intensity fields. Probability density function matching, which performs a bias 
reduction function, is applied to CMORPH-RAW to generate the CMORPH-CRT product. CMORPH-CRT precipitation estimates are then further calibrated via a gauge analysis using an optional interpolation technique to generate the CMORPH-BLD product. Here, 0.25\%3-hourly CMORPHCRT products $(00 z, 03 z, 06 z, 09 z, 12 z, 15 z, 18 z, 21 z)$ from March 2014 to February 2017 were utilized, and the threehourly precipitation data were accumulated to daily values. The CMORPH-CRT 3-hourly precipitation files are forward on the hour given in their file name. For example, a " $00 \mathrm{z}$ " -hour file represents accumulation of rainfall from 0:00 to 2: 59. For a full description of the CMORPH algorithm and its applications, the reader is referred to Joyce et al. [44] and Habib et al. [45]. To obtain a daily-scale CMORPH-CRT product in accord with the time span of daily precipitation collection at the local weather stations (1200-1200 UTC), we assigned a full weight (1.0) for the " $12 z$," " $15 z$," " $18 z$," and " $21 z$ " files for the current day and the "00z," "03z," "06z," and "09z" files for the next day. In this study, the CMORPH-CRT product datasets of the entire study period were downloaded from ftp://ftp.cpc.ncep.noaa.gov/precip/.

2.3.2. TRMM 3B42. The TMPA algorithm was designed by the NASA Goddard Space Flight Center (GSFC). The current TMPA version 7 produces two standard precipitation products (the gauged-adjusted, post real-time research product (TRMM 3B42), and the near real-time product (TRMM 3B42RT)). TRMM 3B42RT applies TRMM Microwave Imager (TMI) dataset for calibration while TRMM 3B42 Combined Instrument (TCI) estimates and GPCC monthly gauge precipitation products are utilized to calibrate TRMM 3B42 for better satellite-based precipitation estimation. Here, 3-hourly TRMM 3B42 products with a spatial resolution of $0.25^{\circ} \times 0.25^{\circ}(00 \mathrm{z}, 03 \mathrm{z}, 06 \mathrm{z}, 09 \mathrm{z}, 12 \mathrm{z}$, $15 z, 18 z$, and 21z) from March 2014 to February 2017 were employed. The TRMM 3B42 3-hourly precipitation files are centered on the hour given in their file name. For example, a " $12 z$ " -hour file represents data from 1030 UTC to 1330 UTC. To obtain a daily-scale TRMM 3B42 product in accord with the time span of daily precipitation collection at the local weather stations (1200-1200 UTC), we assigned a half weight (0.5) to the " $12 \mathrm{z}$ " files for the current and next days and defined a full weight (1.0) for the " $15 z$," " $18 z$," and " $21 z$ " files for the current day and the "00z," "03z," "06z," and "09z" files for the next day.

2.3.3. IMERG V04A and IMERG V05B. The GPM mission, which is a collaborative effort conducted by NASA and JAXA, provides global precipitation estimates and is focused on providing an improved understanding (and therefore forecasting) of extreme weather events and weather systems. IMERG produces three different types of products including an early run (near real-time with a latency of $4 \mathrm{~h}$ ), a late run (reprocessed near real-time with a latency of $12 \mathrm{~h}$ ), and a final run product (gauged-adjusted with a latency of about 4 months). Both the half-hourly and monthly IMERG final run products have been released on a $0.1^{\circ} \times 0.1^{\circ}$ spatial grid. As mentioned above, the IMERG algorithm has been upgraded to Version 05 recently. IMERG V04A and IMERG V05B precipitation products have been released in March 2017 and November 2017, respectively. For more detailed information regarding IMERG, the reader is referred to the IMERG Algorithm Theoretical Basis Document [16, 30, 40, 46]. In this study, the TRMM 3B42 and IMERG product datasets of the entire study period were downloaded from https://pmm.nasa. gov/data-access/downloads/gpm.

Relative to Version 04, Version 05 (1) uses a new GPROF (GPM Profiling Algorithm) to compute precipitation estimates for all microwave sensors as input; (2) provides GPROF estimates from all constellation members in the microwave-only precipitation field (high quality precipitation) over the fully global domain; (3) includes these fully global GPROF estimates in the complete precipitation fields (instantaneous precipitation-calibrated and instantaneous precipitation-uncalibrated) outside the standard IR domain $\left(60^{\circ} \mathrm{N}-\mathrm{S}\right)$, although without morphing or IR fill-in; (4) refines gauge error estimates to provide proper weighting when combined with satellite-only estimates; (5) adds quality index for all half-hourly and monthly products; and (6) does not include TMI (TRMM Microwave Imager) data. Additional information on differences between Versions 04 and 05 can be found in the V05 IMERG Final Run Release Notes [40].

Here, half-hourly final run IMERG V04A and IMERG V05B products were examined between March 2014 and February 2017. The daily IMERG products were generated by summing all 48 half-hourly precipitation estimates. Then, accumulation amounts were multiplied by a factor of 0.5 because the unit of the half-hourly products is in $\mathrm{mm} / \mathrm{h}$.

In order to conduct a fair comparison among the satellite-based precipitation estimates, both the two IMERG products (IMERG V04A and IMERG V05B) were resampled from $0.1^{\circ} \times 0.1^{\circ}$ to $0.25^{\circ} \times 0.25^{\circ}$ using the inverse distance weighting (IDW) interpolation method [47]. The resampled IMERG products are now referred as R-IMERG V04A and R-IMERG V05B, respectively. The IDW interpolation method was used to acquire the spatial rainfall distribution in previous studies $[4,26,48]$. For more detailed information regarding resampling, the reader is referred to Wei et al. [4]. Nevertheless, it should be recognized that its application may result in additional uncertainties.

Overall, CMORPH-CRT, R-IMERG V05B, R-IMERG V04A, and TRMM 3B42 were examined in this paper. Prior to any comparison, all four satellite-based precipitation estimates were aggregated to a $0.25^{\circ}$ spatial and daily temporal resolution.

\subsection{Methodology}

2.4.1. Statistical Analysis. Many previous studies have utilized ground-based rain gauge observations to validate the accuracy of GPM-IMERG products $[4,13,32,37-39,49,50]$. In this study, the daily datasets from 542 separate automatic meteorological stations (Figure 1) in Mainland China were analyzed to evaluate the accuracy of the four satellite-based precipitation products during the period March 2014February 2017. Satellite-based precipitation estimates 
acquired for $0.25^{\circ}$ grid-boxes containing ground stations are compared with gauge-based precipitation observations. In cases where the satellite grid center was close to the ground station, a direct comparison was made. However, in cases where the ground station was surrounded by four grid cells but not particularly close to any of them, an average of the four satellite grid points around the station was used as the basis for comparison. The evaluation of four satellitebased precipitation estimates was conducted based on continuous statistical metrics and categorical statistical metrics. First, annual daily average precipitation analysis was performed. Second, in order to examine seasonal effects, the evaluation analysis was performed separately for each of the four seasons: spring (March to May), summer (June to August), autumn (September to November), and winter (December to February). For regional-based analysis, the whole Mainland China was divided into eight subregions.

To comprehensively evaluate satellite-based precipitation products using gauged precipitation observations, four error indexes: the Pearson linear correlation coefficient (R), Root Mean Square Error (RMSE), Relative Root Mean Square Error (RRMSE), and Relative Bias (RB) were adopted. The definition of these metrics can be found in Chen and Li [37] and Wei et al. [4].

$R$ measures the linear agreement between satellitebased precipitation estimates and rain gauge observations. A perfect positive fit is reflected by a $R$ value is 1 , whereas a weak linear correlation is indicated by $R$ that is close to zero. RMSE measures the absolute average error magnitude. Smaller values of RMSE reflect satellite-based precipitation estimates which are closer to the observations. RRMSE [5, 51-53] normalizes daily precipitation RMSE by the mean daily precipitation of the gauge stations. When RRMSE is more than $50 \%$, such satellite-based precipitation products are considered unreliable. This particular threshold was adopted in previous precipitation assessment studies $[4,37]$. Positive values of RB denote an overestimation of the precipitation amount, while negative values describe an underestimation. We refer the reader to Yuan et al. [35], Chen and Li [37], and Ning et al. [54] for a more detailed description of these statistical indices.

2.4.2. Categorical Statistics. Another assessment technique of satellite-based precipitation estimates is using a contingency table that reflects the frequency of rain/norain estimates in both satellite and gauge-based products (Table 1).

To evaluate the precipitation detection capability, three widely applied categorical statistical metrics, the probability of detection (POD), the false alarm ratio (FAR), and the critical success index (CSI), were used. POD is known as the hit rate, which denotes the fraction of precipitation events correctly detected by the satellite among all actual precipitation events. A perfect POD score is 1 . FAR represents the ratio of the false event among all the events detected by satellite. The ideal FAR score is 0. CSI describes the overall ratio of precipitation events correctly detected by the
TABLE 1: Contingency table to evaluate precipitation occurrence by satellite products.

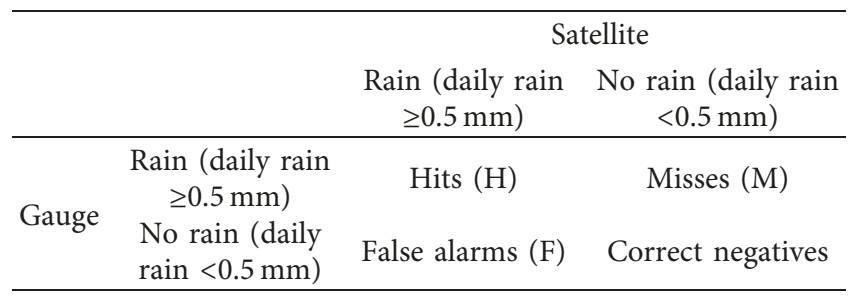

satellite. The optimal value is 1 . POD, FAR, and CSI were calculated as follows:

$$
\begin{aligned}
\mathrm{POD} & =\frac{H}{H+M} \times 100 \%, \\
\mathrm{FAR} & =\frac{F}{H+F} \times 100 \%, \\
\mathrm{CSI} & =\frac{H}{H+M+F} \times 100 \%,
\end{aligned}
$$

where $H$ represents the number of times that observed rain is correctly detected by the satellite; $M$ is the number of times that observed rain is not detected by the satellite; and $F$ is the number of times that rain is detected by satellite but not observed by gauge. POD, FAR, and CSI were only calculated at grid-boxes in which ground stations are located. Here, a threshold of $0.5 \mathrm{~mm} /$ day is used to determine the occurrence of rainfall for any given day while computing categorical statistics.

\section{Results and Analysis}

3.1. Annual Daily Average Precipitation Analysis. Figure 2 shows mean daily precipitation estimates derived from ground rain gauges and four satellite-based precipitation estimates over China. Precipitation accumulation captures by the ground observations generally increase from the northwest (daily average precipitation $<1 \mathrm{~mm} /$ day) to the southeast (daily average precipitation $>3 \mathrm{~mm}$ /day) of China. R-IMERG V05B, TRMM 3B42, and CMORPH-CRT all generally perform well in capturing this coarse-scale pattern. However, finer-scale differences exist among the three satellite-based products. In particular, TRMM 3B42 and CMORPH-CRT show very high accumulated maxima at sporadic individual pixels. These isolated grid points of anomalous high precipitation are more pronounced for CMORPH-CRT than for TRMM $3 \mathrm{~B} 42$. Meanwhile, R-IMERG V05B has a smoother rain pattern which may be attributed to the IMERG product's finer spatiotemporal resolution $\left(0.1^{\circ} /\right.$ half hour). The IMERG products also have more temporal samples of precipitation to efficiently average out anomalous value [37]. According to Figure 2 and the average surface precipitation values sampled over the TP (i.e., $1.1108 \mathrm{~mm} /$ day for R-IMERG V05B, $0.5553 \mathrm{~mm} /$ day for R-IMERG V04A, $1.2498 \mathrm{~mm} /$ day for TRMM 3B42, $1.2515 \mathrm{~mm}$ /day for CMORPH-CRT, respectively), R-IMERG V04A is significantly underestimating precipitation over the TP. The underestimation of IMERG V04A over the TP has been noted previously by Wei [4] and Zhao [13]. 


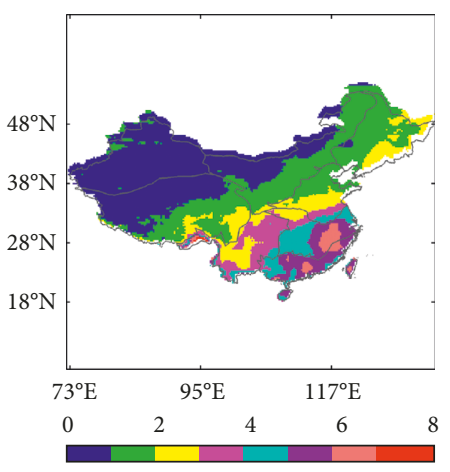

(a)

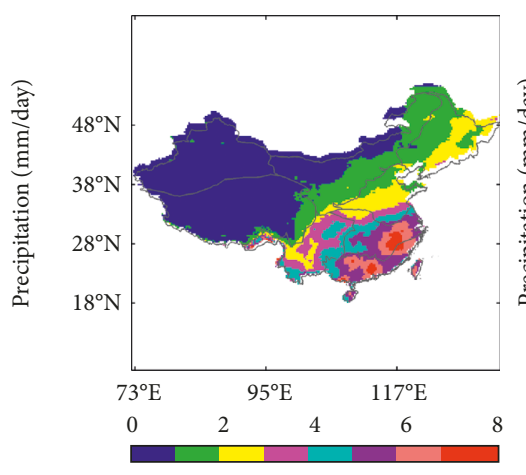

(b)

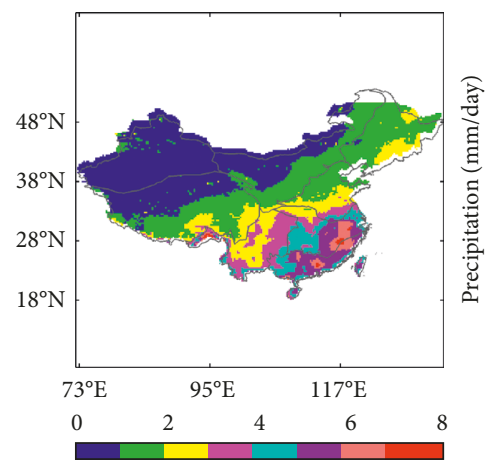

(c)

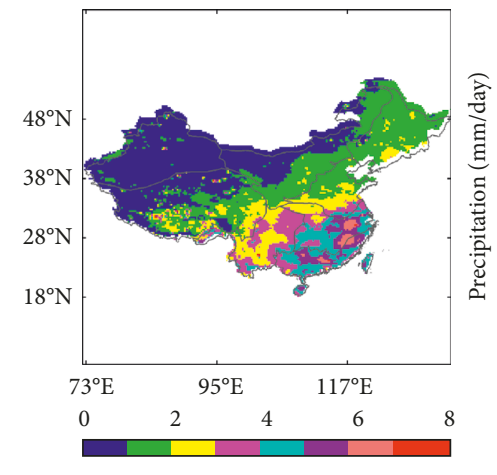

(d)

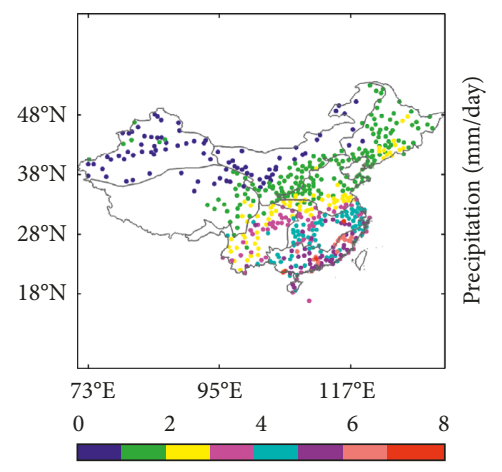

(e)

Figure 2: The spatial distribution of mean daily precipitation (mm/day) (sampled between March 2014 and February 2017 ) at $0.25^{\circ}$ resolution for R-IMERG V05B (a), R-IMERG V04A (b), TRMM 3B42 (c), and CMORPH-CRT (d) over Mainland China. The dots (e) represent mean daily precipitation of 542 rain gauges (sampled between March 2014 and February 2017).

Figure 3 shows scatterplots and fit metrics for the R-IMERG V05B, R-IMERG V04A, TRMM 3B42, and CMORPH-CRT products versus ground-based rain gauge observations for the quantitative comparison of mean daily precipitation over Mainland China throughout the entire study period. According to the R, RMSE, and RRMSE metrics plotted in Figures 3(a) and 3(b), the performance of the R-IMERG V05B product is generally superior to that of the R-IMERG V04A over mainland China throughout the full study period. When compared with R-IMERG V04, the R-IMERG V05B product has a higher $R(0.9759$ for R-IMERG V05B vs. 0.9689 for R-IMERG V04A), a smaller RMSE $(0.4097 \mathrm{~mm} /$ day for R-IMERG V05B vs. $0.4496 \mathrm{~mm} /$ day for R-IMERG V04A), a lower RRMSE (15.44\% for R-IMERG V05B vs. $16.95 \mathrm{~mm} /$ day for R-IMERG V04A), and an inferior RB (5.53\% for R-IMERG V05B vs. $2.14 \%$ for R-IMERG V04A). In comparison with the TRMM 3B42 product's successor (R-IMERG V05B), TRMM 3B42 has an advantage over R-IMERG V05B based on all statistical metrics. Among the four satellite-based precipitation estimates, CMORPH-CRT has the worst performance with the lowest $R(0.9343)$, the largest RMSE $(0.6247 \mathrm{~mm} /$ day $)$, and the highest RRMSE (23.55\%). The RRMSEs of all four satellite-based precipitation products are far below $50 \%$, so all four satellite-based precipitation estimates can be considered reliable over Mainland China during our study period.

Table 2 lists $R, \mathrm{RB}$, RMSE, and RRMSE metrics for average daily precipitation throughout the entire study period for the four satellite-based precipitation estimates over our eight subregions. R-IMERG V04A improves R-IMERG V05B's overestimation over XB with RBs falling from $8.71 \%$ to $1.66 \%$. Meanwhile, R-IMERG V05B slightly overestimates precipitation over DB and $\mathrm{HB}$ subregions with RB values of $15.56 \%$ and $10.57 \%$, respectively. Although this situation is improved in R-IMERG V04A, its RBs are still about $12.48 \%$ over $\mathrm{DB}$ and $9.08 \%$ over HB, while CMORPHCRT shows relatively small RBs $(0.7 \%$ over DB and $4.36 \%$ over HB). The R-IMERG V04A considerably underestimates the precipitation estimates over the $\mathrm{XJ}$ and $\mathrm{TP}$ subregions with the RBs $(-21.8 \%,-46 \%$, respectively). However, this underestimation has been greatly improved by R-IMERG V05B with RBs down to $5.2 \%$ in XJ and $2.78 \%$ in TP, respectively. So, the R-IMERG V05B product demonstrates a better performance than R-IMERG V04A over the XJ and TP subregions. The R-IMERG V05B product exhibits a slightly inferior performance than R-IMERG V04A over $\mathrm{XB}, \mathrm{DB}, \mathrm{HB}$, and CJ with the slightly larger RBs, RMSEs, and RRMSEs. TRMM 3B42 has a slight advantage over both the two IMERG products with relatively smaller RMSEs and RRMSEs over XB, YG, and HB. However, R-IMERG V05B demonstrates better performance than TRMM 3B42, with slightly higher $R$ and relatively smaller RB, RMSE, and RRMSE in XJ. The CMORPH-CRT product has the largest RMSEs and RRMSEs and lowest Rs among the four satellitebased products over XJ, XB, YG, CJ, and HN. Except for XJ and R-IMERG V04A over TP, RRMSEs of all four satellitebased precipitation estimates are far less than 50\% for 


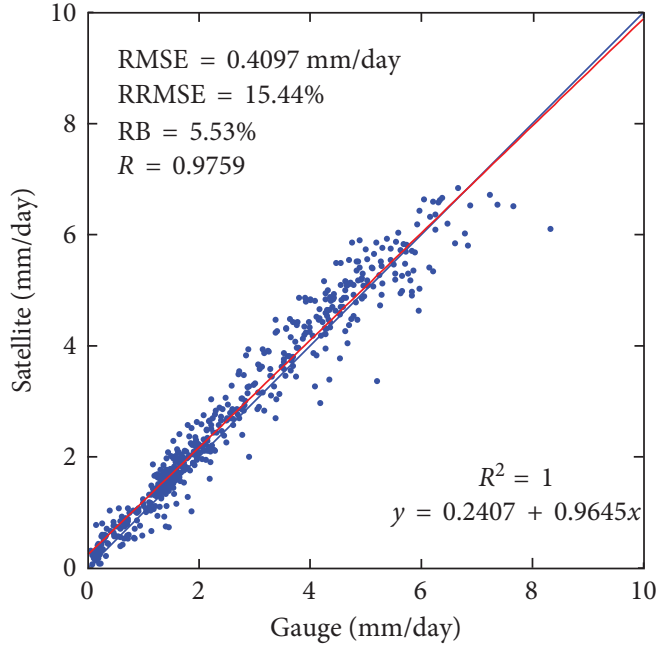

(a)

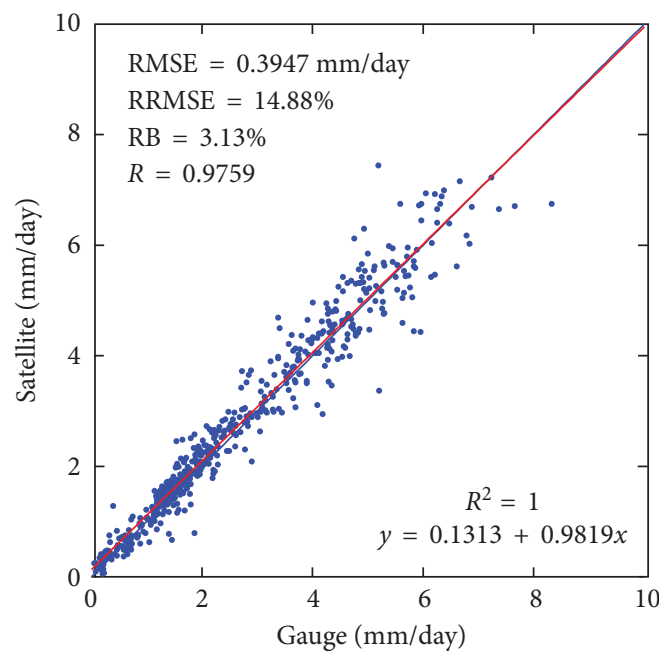

(c)

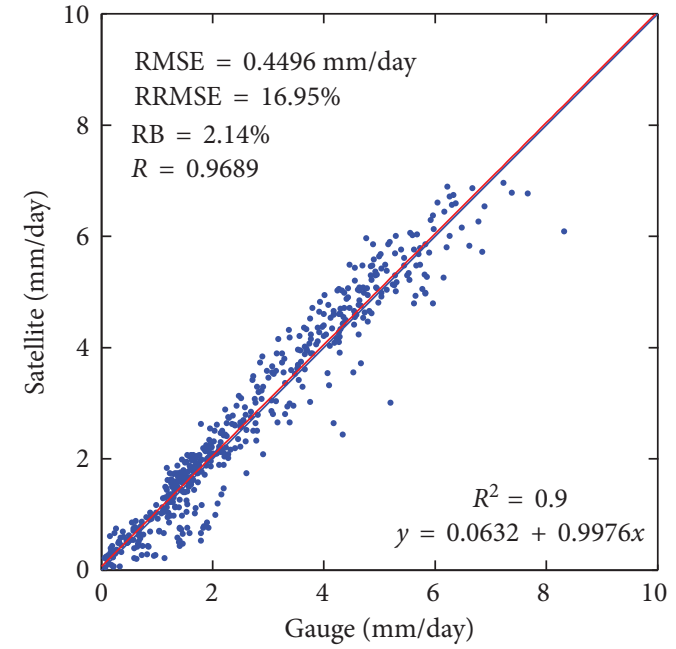

(b)

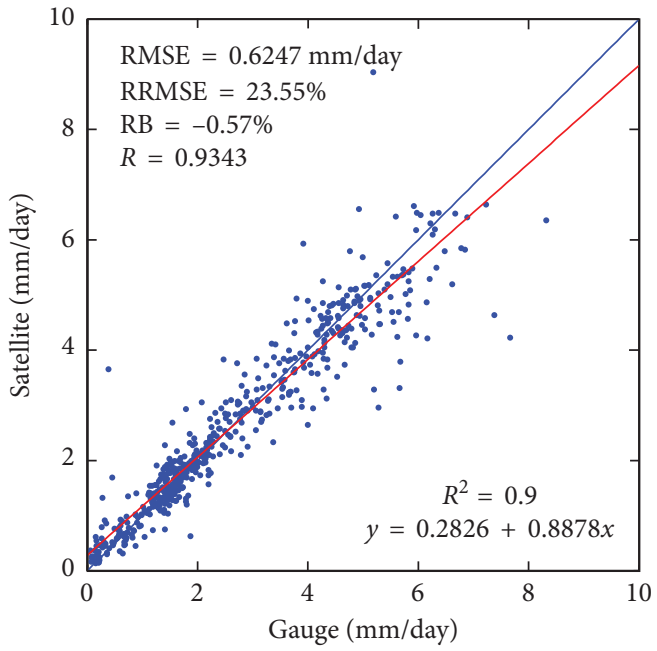

(d)

FIGURE 3: Scatterplots of satellite-based daily average rainfall estimates versus ground-based rain gauge daily average observations for RIMERG V05B (a), R-IMERG V04A (b), TRMM 3B42 (c), and CMORPH-CRT (d) over Mainland China during the period March 2014-February 2017. The blue and red oblique solid lines denote a 1:1 line and a least-squares regression line, respectively.

TABLE 2: $R, \mathrm{RB}, \mathrm{RMSE}$, and RRMSE between different satellite-based products and gauge-based products for mean daily precipitation over eight subregions.

\begin{tabular}{lccccccccc}
\hline Index & Type & XJ & TP & XB & YG & DB & HB & CJ & HN \\
\hline \multirow{4}{*}{$R$} & R-IMERG V05B & 0.72 & 0.91 & 0.94 & 0.68 & 0.869 & 0.71 & 0.908 & 0.84 \\
& R-IMERG V04A & 0.55 & 0.75 & 0.92 & 0.57 & 0.87 & 0.33 & 0.91 & 0.85 \\
& TRMM 3B42 & 0.69 & 0.95 & 0.95 & 0.7 & 0.86 & -0.05 & 0.89 & 0.838 \\
& CMORPH-CRT & 0.28 & 0.88 & 0.89 & 0.29 & 0.8 & 0.19 & 0.84 & 0.58 \\
\hline \multirow{4}{*}{ RB (\%) } & R-IMERG V05B & 5.2 & 2.78 & 8.71 & 4.15 & 15.56 & 10.57 & 6.92 & 0.69 \\
& R-IMERG V04A & -21.8 & -46 & 1.66 & 1.57 & 12.48 & 9.08 & 5.59 & 1.29 \\
& TRMM 3B42 & -7 & 5.39 & 4.92 & 1.68 & 10.68 & 4.57 & 2.96 & 1.56 \\
& CMORPH-CRT & 21.9 & 7.53 & 5.27 & 0.45 & 0.7 & 4.36 & 0.35 & -6.62 \\
\hline RMSE (mm/day) & R-IMERG V05B & 0.29 & 0.26 & 0.19 & 0.56 & 0.31 & 0.31 & 0.54 & 0.507 \\
& R-IMERG V04A & 0.37 & 0.74 & 0.18 & 0.64 & 0.268 & 0.28 & 0.5 & 0.506 \\
& TRMM 3B42 & 0.3 & 0.21 & 0.16 & 0.54 & 0.273 & 0.25 & 0.53 & 0.52 \\
& CMORPH-CRT & 0.61 & 0.32 & 0.23 & 1.08 & 0.22 & 0.29 & 0.65 & 0.88 \\
\hline \multirow{3}{*}{ RRMSE (\%) } & R-IMERG V05B & 54.91 & 18.98 & 17.94 & 17.76 & 19.16 & 15.72 & 13.2 & 9.65 \\
& R-IMERG V04A & 69.78 & 54.36 & 17.26 & 20.33 & 16.43 & 14.38 & 12.3 & 9.62 \\
& TRMM 3B42 & 57.87 & 15.4 & 14.89 & 17 & 16.73 & 12.57 & 12.89 & 9.98 \\
& CMORPH-CRT & 116.7 & 23.24 & 21.33 & 34.1 & 13.71 & 14.41 & 16.04 & 16.71 \\
\hline
\end{tabular}


subregions. Conversely, all four satellite-based precipitation estimates are unreliable over the arid XJ region based on their mutual RRMSE values (54.91\% for R-IMERG V05B, $69.78 \%$ for R-IMERG V04A, 57.87\% for TRMM 3B42 and $116.7 \%$ for CMORPH-CRT, respectively). The reasons behind this unreliability may be related to high latitude or the poor detection ability of the shallow orographic precipitation for passive microwave and IR satellites [13, 38].

3.2. Seasonal Scale Precipitation Analysis. Over China, spatial patterns of daily average R-IMERG V05B, R-IMERG V04A, TRMM 3B42, and CMORPH-CRT precipitation estimates for each individual season (during the period March 2014-February 2017) are shown in Figure 4. In general, all four satellite-based products capture the general precipitation patterns for four seasons over most parts of China. Precipitation rates peak in summer, with slightly lower amounts falling during autumn. TRMM 3B42 (Figures 4(i)-4(l)) and CMORPH-CRT (Figures 4(m)-4(p)) contain isolated grid points of anomalously more precipitation in each season, just as shown previously in annual precipitation results.

In spring, the two IMERG products (Figures 4(a) and 4(e)) show more precipitation than the other two satellite-based products (Figures $4(\mathrm{i})$ and $4(\mathrm{~m})$ ) over the eastern DB region. Likewise in winter, the two IMERG products (Figures $4(\mathrm{~d})$ and $4(\mathrm{~h})$ ) also show more precipitation than the other two satellite-based products (Figures $4(\mathrm{l})$ and $4(\mathrm{p})$ ) in areas bordering CJ and HN. Compared with the R-IMERG V05B and gauge-based products, R-IMERG V04A underestimates precipitation over the $\mathrm{XJ}$ region for all seasons except summer based on daily average precipitation accumulations $(0.464 \mathrm{~mm} /$ day, $0.468 \mathrm{~mm} /$ day, $0.31 \mathrm{~mm} /$ day in spring; $0.53 \mathrm{~mm} /$ day, $0.49 \mathrm{~mm} /$ day, $0.32 \mathrm{~mm} /$ day in Autumn; $\quad 0.22 \mathrm{~mm} /$ day, $\quad 0.2 \mathrm{~mm} /$ day, $0.04 \mathrm{~mm} /$ day in Winter for R-IMERG V05B, Gauge, and R-IMERG V04A, respectively). Relative to R-IMERG V05B, the R-IMERG V04A product exhibits a significant underestimation of the precipitation over TP in every season according to Figures $4(\mathrm{a})-4(\mathrm{~h}), 4(\mathrm{q})-4(\mathrm{t})$, and the mean surface precipitation $(1.04 \mathrm{~mm} /$ day, $1 \mathrm{~mm} /$ day, $0.29 \mathrm{~mm} /$ day in spring; $3.14 \mathrm{~mm} /$ day, $3.17 \mathrm{~mm} /$ day, $2.04 \mathrm{~mm}$ /day in Summer; $1.32 \mathrm{~mm} /$ day, $\quad 1.33 \mathrm{~mm} /$ day, $0.61 \mathrm{~mm} /$ day in Autumn; $0.09 \mathrm{~mm} /$ day, $0.12 \mathrm{~mm} /$ day, $0.01 \mathrm{~mm} /$ day in Winter for R-IMERG V05B, Gauge and R-IMERG V04A, respectively).

Seasonal differences in precipitation estimates derived from the R-IMERG V05B, R-IMERG V04A, TRMM 3B42, and CMORPH-CRT products against rain gauge observations over mainland China have been summarized in Figure 5. During the annual average daily precipitation analysis showed earlier in Figure 3, R-IMERG V04A demonstrated worse performance than R-IMERG V05B over Mainland China. Likewise, at the seasonal scale, compared with R-IMERG V05B, R-IMERG V04A exhibits poorer performance versus rain gauge observations with the larger RMSEs $(0.54 \mathrm{~mm} /$ day vs. $0.6 \mathrm{~mm} /$ day in spring; $0.88 \mathrm{~mm} /$ day vs. $0.95 \mathrm{~mm} /$ day in summer; $0.48 \mathrm{~mm} /$ day vs. $0.53 \mathrm{~mm} /$ day in autumn; and $0.257 \mathrm{~mm} /$ day vs. $0.26 \mathrm{~mm} /$ day in winter for
R-IMERG V05B, and R-IMERG V04A, respectively), relative higher RRMSEs $(20.05 \%$ vs. $22.15 \%$ in spring; $19 \%$ vs. $20.66 \%$ in summer; $20.1 \%$ vs. $22 \%$ in autumn; $29.45 \%$ vs. $30.26 \%$ in winter for R-IMERG V05B and R-IMERG V04A, respectively), and relative lower Rs (0.979 vs. 0.973 in spring; 0.95 vs. 0.94 in summer; 0.95 vs. 0.94 in autumn for R-IMERG V05B and R-IMERG V04A, respectively). Based on RMSE, RRMSE, and $R$ metric results, TRMM 3B42 shows the best performance and CMORPH-CRT gives the worst performance among the four satellite-based precipitation estimates over Mainland China at the annual scale.

At the seasonal scale, among the four satellite-based precipitation estimates, TRMM $3 \mathrm{~B} 42$ has the smallest RMSEs ( $0.53 \mathrm{~mm} /$ day for spring, $0.82 \mathrm{~mm} /$ day for summer), the lowest RRMSEs (19.75\% for spring, $17.84 \%$ for summer) and the highest Rs (0.981 for spring, 0.96 for summer) in spring and summer while CMORPH-CRT has the largest RMSEs (ranging from $22.75 \%$ in summer to $102.58 \%$ in winter), highest RRMSEs (ranging from $0.71 \mathrm{~mm} /$ day in autumn to $1.05 \mathrm{~mm}$ /day in summer), and lowest Rs (ranging from 0.66 in winter to 0.95 in spring) in every season. At the same time, precipitation estimates from R-IMERG V05B are higher than the gauge observations and exhibit consistently positive RBs (from $4.27 \%$ in winter to $6.12 \%$ in autumn). Precipitation estimates from R-IMERG V04A and TRMM $3 \mathrm{~B} 42$ are lower than gauge observations only in winter on the basis of RBs, while, CMORPH-CRT precipitation estimates are higher than the gauge observations only in spring according to RBs. The underestimation by the satellite-based products may be influenced by the presence of snow and icecovered surfaces during the winter, which degrades the performance of PMW-based retrieval algorithms [55].

Except for CMORPH-CRT in winter, all RRMSEs for the four satellite-based precipitation estimates are less than $50 \%$. If winter is removed, all RRMSEs are less than $30 \%$. Hence, except for the specific instances noted above, all four satellite-based precipitation estimates are generally reliable and can effectively capture seasonal patterns in precipitation.

Table 3 lists $R, \mathrm{RB}, \mathrm{RMSE}$, and RRMSE values (subdivided by season) for daily average precipitation derived from the four satellite-based precipitation estimates against rain gauge observations over eight subregions. The R-IMERG V04A product shows a severe underestimation over XJ and TP (RB ranging from $-31.41 \%$ in spring to $-77.79 \%$ in winter over $\mathrm{XJ}$, ranging from $-33.99 \%$ in summer to $-89.63 \%$ in winter over $\mathrm{TP}$, respectively) in each season (except for summer in $\mathrm{XJ}$ ). However, the R-IMERG V05B product obviously improves this earlier underestimation in every season over these two subregions. For example, R-IMERG V05B decreases the absolute RB by $30.61 \%$ over XJ and $65.83 \%$ over TP in spring. The underestimation of R-IMERG V04A in each season over $\mathrm{XJ}$ and the TP is also consistent with the earlier results during annual daily average precipitation analysis (see Section 3.1). The R-IMERG V05B product consistently demonstrates a better performance than R-IMERG V04A with higher Rs, smaller RBs (except for summer in XJ), RMSEs, and lower RRMSEs over XJ and the TP in all seasons. During annual daily average precipitation analysis, TRMM $3 B 42$ has an advantage over R-IMERG V05B based on its smaller RMSE, 


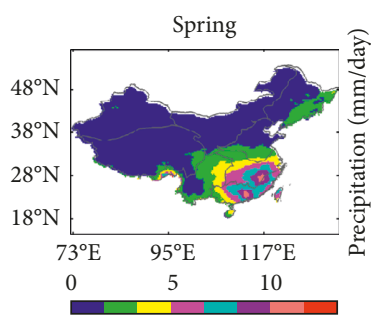

(a)

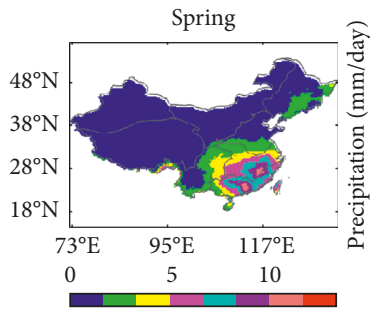

(e)

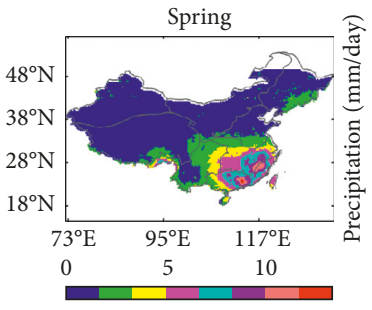

(i)

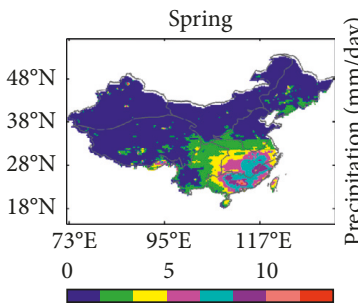

(m)

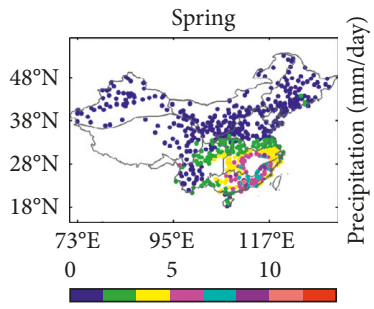

(q)

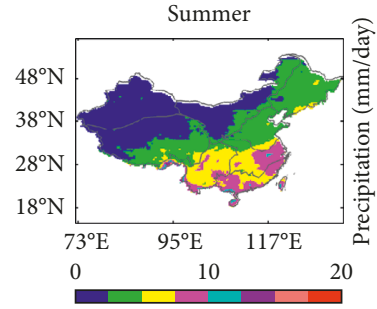

(b)

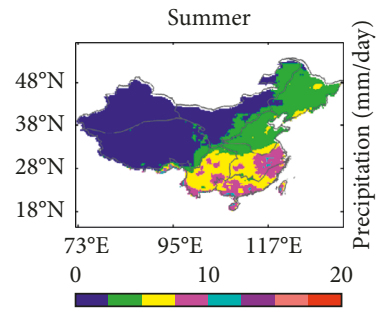

(f)

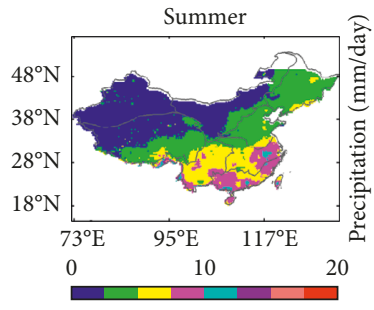

(j)

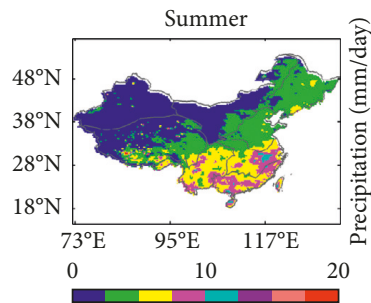

(n)

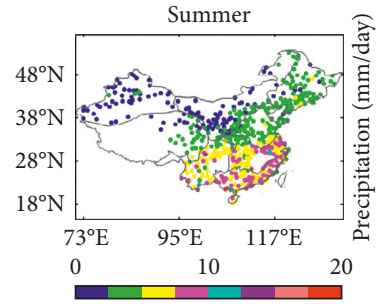

(r)

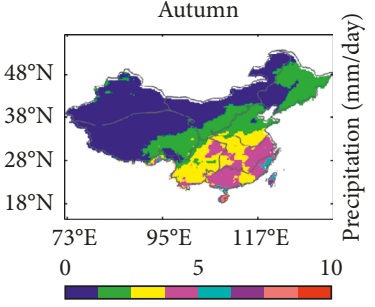

(c)

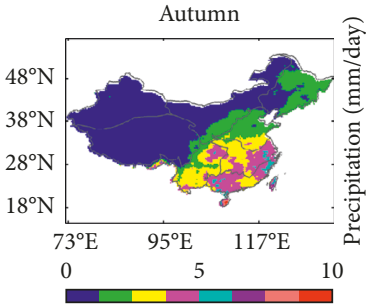

(g)

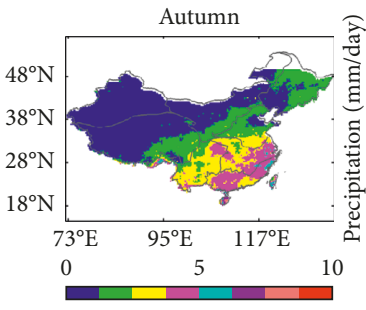

(k)

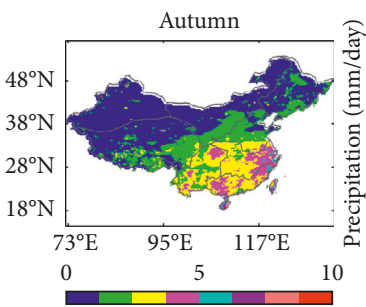

(o)

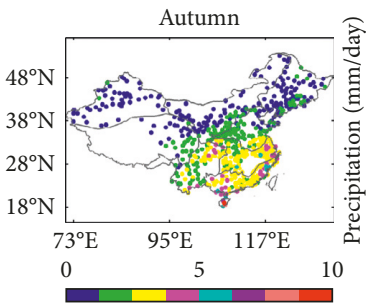

(s)

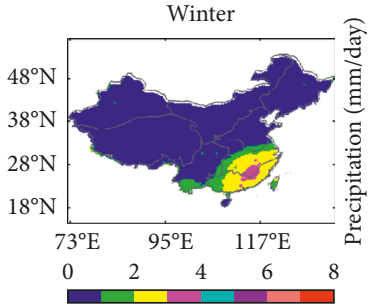

(d)

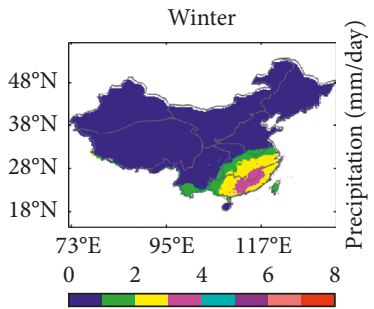

(h)

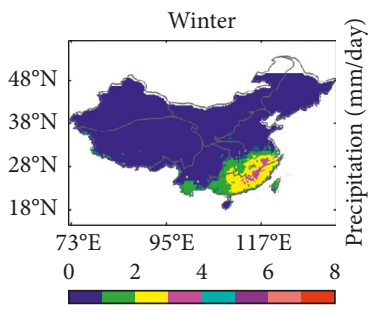

(l)

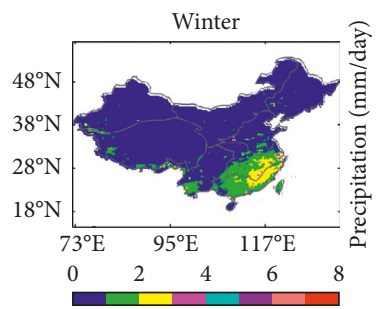

(p)

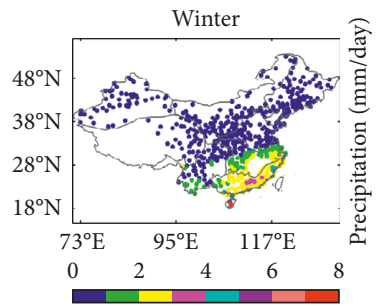

(t)

FIGURE 4: Maps of seasonal daily average precipitation ( $\mathrm{mm} /$ day) at a $0.25^{\circ}$ spatial resolution derived from R-IMERG V05B (a-d), R-IMERG V04A (e-h), TRMM 3B42 (i-l), and CMORPH-CRT (m-p) for spring, summer, autumn, and winter over Mainland China during the period March 2014-February 2017. The dots (q-t) represent the seasonal daily average precipitation (mm/day) of 542 rain gauges (sampled between March 2014 and February 2017).

RB, and RRMSE metrics (Figures 3(a) and 3(c)). On the regional scale, except for $\mathrm{XJ}$ and $\mathrm{HN}$, TRMM 3B42 shows a better performance than R-IMERG V05B with lower RMSEs and RRMSEs (Table 2) over all subregions. At the seasonal scale, TRMM 3B42 outperforms R-IMERG V05B and demonstrates smaller RMSEs and RRMSEs in Table 3 (over TP, DB, HN, CJ, and HN in spring; over the seven subregions except for $\mathrm{HB}$ in summer; over the TP, $\mathrm{XB}, \mathrm{YG}$, and $\mathrm{HN}$ in autumn, respectively). However, in winter, TRMM $3 \mathrm{~B} 42$ is inferior to R-IMERG V05B in terms of RMSEs and RRMSEs (in Table 3) over all the subregions (except for XJ and XB).

Over the XJ region, satellite-based precipitation estimates are unreliable for all seasons according to their RRMSEs (all more than 50\%) in Table 3. This unreliability is 


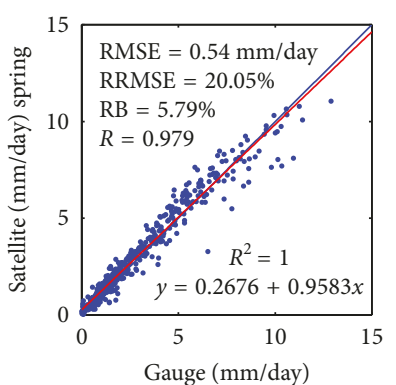

(a)

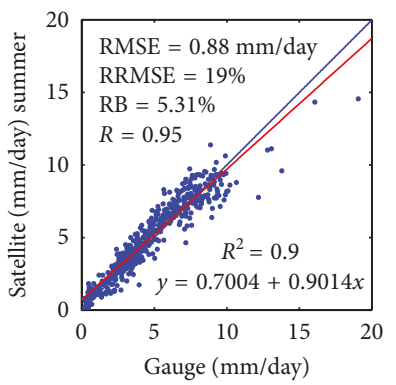

(e)

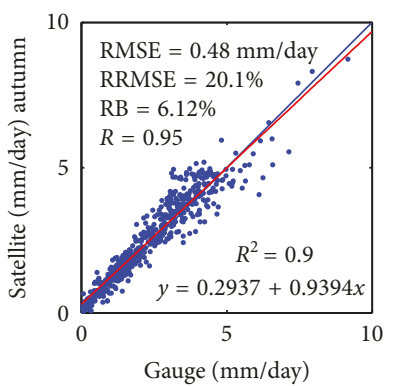

(i)

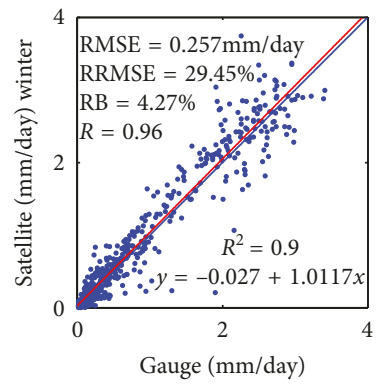

(m)

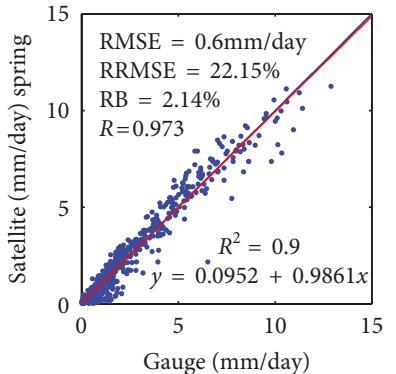

(b)

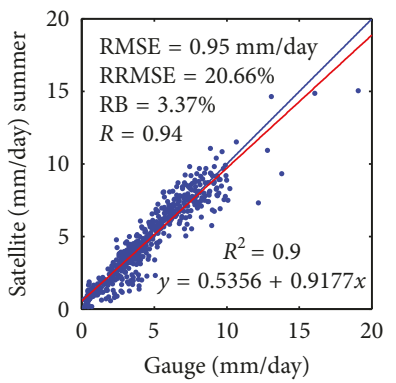

(f)

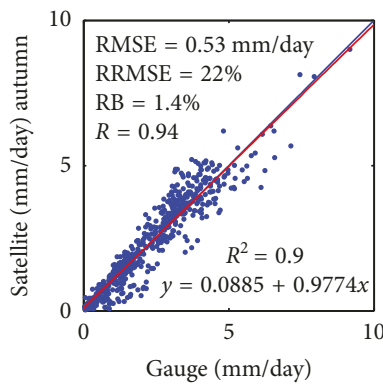

(j)

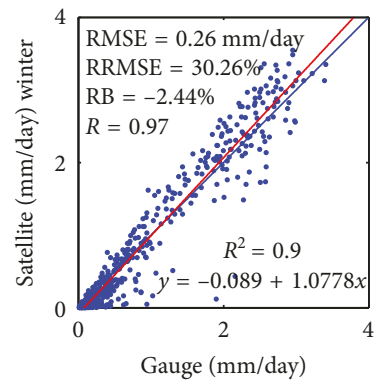

(n)

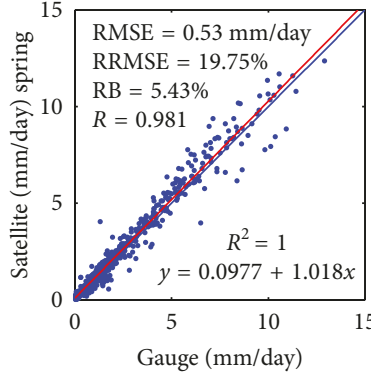

(c)

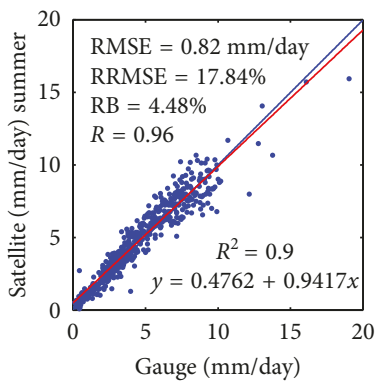

(g)

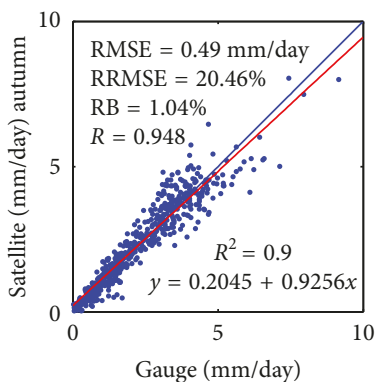

(k)

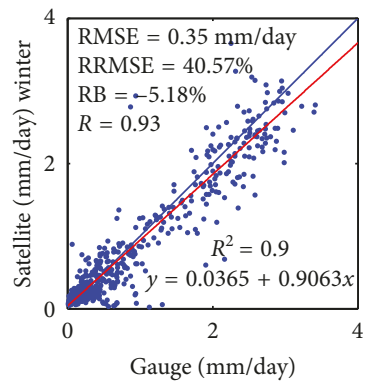

(o)

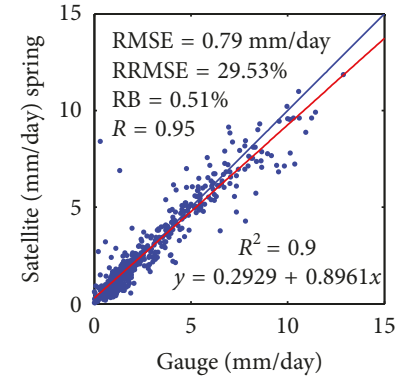

(d)

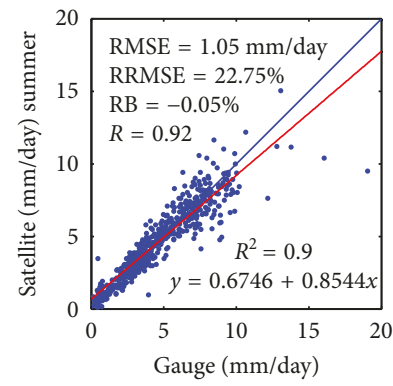

(h)

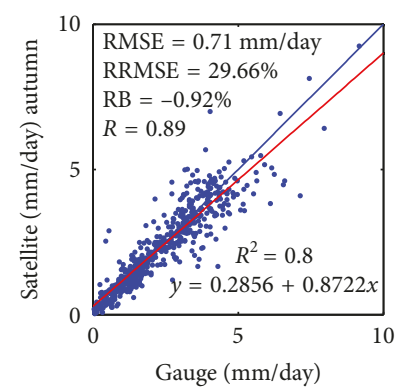

(l)

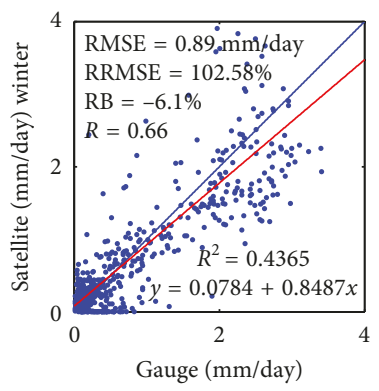

(p)

FIGURE 5: Scatterplots of satellite-based versus ground-based average daily rainfall estimates for the four seasons over Mainland China for R-IMERG V05B (a), (e), (i), and (m), R-IMERG V04A (b), (f), (j), and (n), TRMM 3B42 (c), (g), (k), and (o) and CMORPH-CRT $(\mathrm{d}),(\mathrm{h}),(\mathrm{l})$, and $(\mathrm{p})$.

in line with the result during annual daily average precipitation analysis (see Section 3.1). Except for XJ, all the satellite-based precipitation estimates are reliable in all regions with the RRMSEs less than 50\% (except for R-IMERG V04A over the TP) during spring, summer, and autumn. However, in winter, both IMERG products are unreliable over XJ, TP, and XB with RRMSE ranging from 57.91\% to $115.7 \%$, TRMM 3B42 is unreliable over XJ, TP, YG, and DB with RRMSE ranging from $53.99 \%$ to $91.39 \%$, and CMORPHCRT is unreliable over the eight subregions (except for HN) with RRMSE ranging from $65.05 \%$ to $276.6 \%$. In general, RRMSE results (in Table 3) indicate that all the satellite-based precipitation estimates have a relatively inferior performance in winter versus the other three seasons.

3.3. Probability Distribution Function of Precipitation Intensity Analysis. The probability distribution function of rain-rate concurrence $(\mathrm{PDFc})$ can reveal detailed information on the spatiotemporal inhomogeneity of 
TABLE 3: Statistical metrics for seasonal daily mean precipitation over the 8 subregions in China.

\begin{tabular}{|c|c|c|c|c|c|c|c|c|c|c|}
\hline Index & Seasons & Type & $\mathrm{XJ}$ & $\mathrm{TP}$ & $\mathrm{XB}$ & YG & $\mathrm{DB}$ & $\mathrm{HB}$ & $\mathrm{CJ}$ & $\mathrm{HN}$ \\
\hline \multirow{16}{*}{$R$} & \multirow{4}{*}{ Spring } & R-IMERG V05B & 0.77 & 0.9 & 0.96 & 0.85 & 0.82 & 0.938 & 0.96 & 0.938 \\
\hline & & R-IMERGV04A & 0.59 & 0.72 & 0.91 & 0.73 & 0.8 & 0.936 & 0.953 & 0.94 \\
\hline & & TRMM 3B42 & 0.68 & 0.93 & 0.93 & 0.82 & 0.77 & 0.94 & 0.955 & 0.95 \\
\hline & & CMORPH-CRT & 0.1 & 0.74 & 0.81 & 0.61 & 0.48 & 0.87 & 0.92 & 0.9 \\
\hline & \multirow{4}{*}{ Summer } & R-IMERG V05B & 0.622 & 0.9 & 0.9 & 0.73 & 0.78 & 0.87 & 0.87 & 0.86 \\
\hline & & R-IMERGV04A & 0.41 & 0.68 & 0.9 & 0.66 & 0.77 & 0.9 & 0.88 & 0.84 \\
\hline & & TRMM 3B42 & 0.62 & 0.95 & 0.93 & 0.78 & 0.79 & 0.88 & 0.88 & 0.87 \\
\hline & & CMORPH-CRT & 0.46 & 0.91 & 0.87 & 0.61 & 0.83 & 0.88 & 0.85 & 0.67 \\
\hline & \multirow{4}{*}{ Autumn } & R-IMERG V05B & 0.75 & 0.94 & 0.93 & 0.68 & 0.78 & 0.92 & 0.7 & 0.88 \\
\hline & & R-IMERGV04A & 0.567 & 0.8 & 0.91 & 0.64 & 0.8 & 0.92 & 0.71 & 0.87 \\
\hline & & TRMM 3B42 & 0.57 & 0.96 & 0.94 & 0.71 & 0.68 & 0.92 & 0.66 & 0.85 \\
\hline & & CMORPH-CRT & 0.39 & 0.9 & 0.92 & 0.44 & 0.55 & 0.85 & 0.63 & 0.74 \\
\hline & \multirow{4}{*}{ Winter } & R-IMERG V05B & 0.69 & 0.78 & 0.5 & 0.77 & 0.86 & 0.94 & 0.95 & 0.78 \\
\hline & & R-IMERGV04A & 0.57 & 0.73 & 0.47 & 0.69 & 0.79 & 0.96 & 0.96 & 0.81 \\
\hline & & TRMM 3B42 & 0.59 & 0.64 & 0.56 & 0.48 & 0.87 & 0.78 & 0.83 & 0.77 \\
\hline & & CMORPH-CRT & -0.22 & 0.38 & 0.14 & 0.22 & -0.16 & 0.51 & 0.55 & 0.31 \\
\hline \multirow{16}{*}{ RB (\%) } & \multirow{4}{*}{ Spring } & R-IMERG V05B & -0.8 & 3.95 & 10.43 & 1.42 & 19.5 & 17 & 6.57 & 1.77 \\
\hline & & R-IMERGV04A & -31.41 & -69.78 & -2.46 & -3.67 & 15.73 & 16.18 & 5.7 & 2.37 \\
\hline & & TRMM 3B42 & -8.35 & 10.12 & 6.21 & 2.73 & 4.51 & 6.65 & 6.33 & 5.53 \\
\hline & & CMORPH-CRT & 62.96 & 9.24 & 8.44 & -2.09 & 2.77 & 8.08 & -0.47 & -3.89 \\
\hline & \multirow{5}{*}{ Summer } & R-IMERG V05B & 3.72 & 3.62 & 10.55 & 6.65 & 14.17 & 9.03 & 4.68 & -0.54 \\
\hline & & R-IMERGV04A & -0.39 & -33.99 & 8.33 & 6.06 & 15.69 & 9.42 & 3.63 & -0.44 \\
\hline & & TRMM 3B42 & -3.28 & 4.17 & 6.43 & 4.59 & 11.47 & 8.64 & 2.14 & 2.19 \\
\hline & & CMORPH-CRT & 13.12 & 2.75 & 4.69 & -0.32 & 6.37 & 3.25 & 1 & -6.48 \\
\hline & & R-IMERG V05B & 10.4 & 2.75 & 8.5 & 4.1 & 13.04 & 6.94 & 8.29 & 2.83 \\
\hline & \multirow{3}{*}{ Autumn } & R-IMERGV04A & -34.01 & -52.7 & 0.85 & 1.44 & 7.47 & 4.95 & 7.04 & 2.38 \\
\hline & & TRMM 3B42 & -28.72 & 4.25 & 1.26 & 0.53 & 6.46 & -0.66 & 3.36 & 0.13 \\
\hline & & CMORPH-CRT & 23.28 & 11 & 2.78 & -0.37 & -0.61 & -2.07 & 1.58 & -6.79 \\
\hline & \multirow{4}{*}{ Winter } & R-IMERG V05B & 13.5 & -28.4 & -28.86 & -12.75 & 25.16 & 21.34 & 14.35 & -1.89 \\
\hline & & R-IMERGV04A & -77.79 & -89.63 & -72.46 & -21.34 & -17.15 & 3.36 & 10.31 & 2.33 \\
\hline & & TRMM 3B42 & 31.67 & 10.78 & 7.72 & -24.91 & 42.46 & -11.64 & -4.35 & -8.38 \\
\hline & & CMORPH-CRT & -34.64 & 79.89 & 19.06 & 16.5 & -65.76 & 35.76 & -2.94 & -13.94 \\
\hline \multirow{16}{*}{ RMSE (mm/day) } & & R-IMERG V05B & 0.31 & 0.26 & 0.16 & 0.59 & 0.35 & 0.36 & 0.63 & 0.908 \\
\hline & & R-IMERGV04A & 0.41 & 0.8 & 0.2 & 0.79 & 0.32 & 0.35 & 0.62 & 0.88 \\
\hline & Spring & TRMM 3B42 & 0.35 & 0.24 & 0.18 & 0.65 & 0.28 & 0.25 & 0.62 & 0.89 \\
\hline & & CMORPH-CRT & 1.34 & 0.49 & 0.29 & 0.97 & 0.45 & 0.35 & 0.72 & 1.13 \\
\hline & & R-IMERG V05B & 0.63 & 0.58 & 0.46 & 1.2 & 0.74 & 0.68 & 0.96 & 1.16 \\
\hline & & R-IMERGV04A & 0.73 & 1.37 & 0.45 & 1.35 & 0.79 & 0.633 & 0.91 & 1.19 \\
\hline & Summer & TRMM 3B42 & 0.62 & 0.49 & 0.38 & 1.1 & 0.7 & 0.7 & 0.93 & 1.09 \\
\hline & & CMORPH-CRT & 0.8 & 0.55 & 0.48 & 1.39 & 0.6 & 0.58 & 1.05 & 1.75 \\
\hline & & R-IMERG V05B & 0.28 & 0.25 & 0.25 & 0.65 & 0.27 & 0.33 & 0.64 & 0.67 \\
\hline & & R-IMERGV04A & 0.36 & 0.81 & 0.26 & 0.7 & 0.22 & 0.32 & 0.62 & 0.69 \\
\hline & Autumn & TRMM 3B42 & 0.35 & 0.22 & 0.22 & 0.63 & 0.28 & 0.31 & 0.63 & 0.74 \\
\hline & & CMORPH-CRT & 0.55 & 0.34 & 0.26 & 1.3 & 0.29 & 0.43 & 0.72 & 0.98 \\
\hline & & R-IMERG V05B & 0.19 & 0.07 & 0.08 & 0.28 & 0.14 & 0.13 & 0.33 & 0.42 \\
\hline & & R-IMERGV04A & 0.21 & 0.14 & 0.11 & 0.35 & 0.13 & 0.11 & 0.27 & 0.44 \\
\hline & Winter & TRMM 3B42 & 0.17 & 0.08 & 0.06 & 0.56 & 0.18 & 0.17 & 0.52 & 0.438 \\
\hline & & CMORPH-CRT & 0.28 & 0.18 & 0.12 & 2.02 & 0.36 & 0.39 & 1 & 0.89 \\
\hline & & R-IMERG V05B & 66.34 & 26.42 & 20.06 & 24.89 & 25.97 & 23.72 & 13.65 & 14.18 \\
\hline & Snring & R-IMERGV04A & 88.06 & 79.86 & 24.36 & 33.29 & 23.79 & 23.51 & 13.5 & 13.77 \\
\hline & Spring & TRMM 3B42 & 75.21 & 23.74 & 22.68 & 27.55 & 21.4 & 16.76 & 13.52 & 13.95 \\
\hline & & CMORPH-CRT & 286.2 & 48.64 & 36.37 & 40.92 & 34.14 & 23.41 & 15.52 & 17.72 \\
\hline & & R-IMERG V05B & 65.22 & 19.2 & 22.27 & 20.31 & 20.75 & 18.21 & 14.8 & 14.65 \\
\hline & & R-IMERGV04A & 76.22 & 45.27 & 21.48 & 22.27 & 21.97 & 16.9 & 14 & 15.05 \\
\hline & Summer & TRMM 3B42 & 65.18 & 16.07 & 18.1 & 18.09 & 19.62 & 18.74 & 14.3 & 13.8 \\
\hline & & CMORPH-CRT & 82.99 & 18.01 & 23.03 & 22.93 & 16.67 & 15.51 & 16.22 & 22.11 \\
\hline RRMSE (\%) & & R-IMERG V05B & 58.57 & 19.36 & 20.43 & 21.05 & 21.81 & 15.03 & 18.09 & 15.5 \\
\hline & & R-IMERGV04A & 76.04 & 62.77 & 20.97 & 22.86 & 17.62 & 14.3 & 17.47 & 15.91 \\
\hline & Autumn & TRMM 3B42 & 73.97 & 17.06 & 17.45 & 20.47 & 22.59 & 13.84 & 17.58 & 17.13 \\
\hline & & CMORPH-CRT & 115.8 & 26.59 & 20.86 & 42.14 & 23.06 & 19.24 & 20.2 & 22.84 \\
\hline & & R-IMERG V05B & 93.91 & 58.73 & 57.91 & 38.43 & 43.2 & 32.12 & 21.81 & 17.76 \\
\hline & & R-IMERGV04A & 111.2 & 115.7 & 86.18 & 48.23 & 39.77 & 27.04 & 17.89 & 18.58 \\
\hline & Winter & TRMM 3B42 & 91.39 & 64.61 & 47.22 & 77.27 & 53.99 & 40.92 & 34 & 18.45 \\
\hline & & CMORPH-CRT & 146.2 & 149.9 & 87.95 & 276.6 & 111 & 93.15 & 65.05 & 37.6 \\
\hline
\end{tabular}


precipitation events and provide insight into the dependence of estimate errors on precipitation rate and the potential of these errors on hydrological applications. As a result, the distribution of rainfall frequencies with different intensities for rainfall events is used in many studies to evaluate the quality of satellite-based precipitation products [13, 38, 39]. Here, R-IMERG V05B, R-IMERG V04A, TRMM 3B42, and COMRPH-CRT is compared to gauge-based precipitation estimates over mainland China and the eight Chinese subregions during the whole study period (Figure 6).

As shown in Figure 6, both IMERG products and CMORPH-CRT overestimate the frequency of light precipitation $(<1 \mathrm{~mm} /$ day) and show a slight underestimation in rain rate bins over $2 \mathrm{~mm} /$ day. This result may be related to the fact that the IMERG PMW- (passive microwave-) based algorithm excels at estimating heavy, convective precipitation events and struggles with the detection of the shallow and warm precipitation. Compared with R-IMERG V05B, R-IMERG V04A slightly overestimates light precipitation events $(<1 \mathrm{~mm} /$ day $)$ and underestimate precipitation events for rain rate bins greater than $10 \mathrm{~mm} /$ day over XJ, TP, YG, and HN. Meanwhile, R-IMERG V05B is closer to the PDF of gauges, indicating the improved detection capability of R-IMERG V05B compared to R-IMERG V04A. In addition, the two IMERG products have a closer performance over XB, DB, HB, and CJ. For all of mainland China, TRMM 3B42 agrees best with the PDFc of daily rain gauge estimates among all four satellite-based precipitation products (Figure 6(a)).

3.4. Contingency Statistics. Figure 7 compares spatial maps of POD, FAR, and CSI statistics for all four satellite-based precipitation products over Mainland China. The POD and CSI of these products show a similar spatial pattern in that they generally increase from the northwest to the southeast of mainland China. In contrast, FAR shows a decrease from the northwest to the southeast. In other words, four satellitebased precipitation estimates agree well with the gauge data over the eastern and southern parts of Mainland China because these regions have relatively more moderate and heavy precipitation events and relatively flatter topography. The four satellite-based precipitation estimates show a slightly inferior performance over the northern and western parts of China. This result may be related to multiple factors including complex topography and climate, the altitude in mountainous terrain, sparse and uneven rain gauge distribution in mountain areas, and our particular optional interpolation technique. In addition, finer-scale differences still exist among the four satellite-based products. For example, over XJ, R-IMERG V05B has an advantage over R-IMERG V04A based on their respective POD results (Figures $7(\mathrm{a})$ and $7(\mathrm{~d})$ ).

Figure 8 compares POD, FAR, and CSI performance statistics samples between the satellite-based precipitation estimates and the precipitation gauges over mainland China and eight subregions. In general, all the four satellitebased precipitation estimates have low PODs $(<0.66)$ and CSIs $(<0.44)$ and high FARs $(>0.4)$ over various subregions, especially over XJ, XB, DB, and $\mathrm{HB}$. At the regional scale, all four satellite-based precipitation estimates have a better performance over $\mathrm{YG}, \mathrm{CJ}$, and $\mathrm{HN}$ than over the other subregions (except for TP). Over TP, compared with the other three satellite-based precipitation estimates, R-IMERG V04A has a worse performance with a lower POD in Figure 8(a). For example, POD increased by $48.4 \%$ from R-IMERG V04A to R-IMERG V05B, 13.6\% from R-IMERG V04A to TRMM 3B42, and 27.6\% from R-IMERG V04A to CMORPH-CRT. This result is consistent with the precipitation occurrence results shown above in Figure 6(c). The two IMERG products demonstrate similar performance over all the eight subregions (except for XJ and TP) with the closer PODs, FARs, and CSIs. Over XJ and TP, compared to R-IMERG V04A, R-IMERG V05B demonstrates improved an improved capability for detecting precipitation events, as indicated by its larger POD ( 0.4213 vs. 0.2839 over XJ and 0.6364 vs. 0.458 over TP).

\section{Discussion}

A number of studies have already assessed the quality of satellite-based precipitation products over China $[4,13$, 37-39]. However, IMERG V05B was recently released on November 2017 and has not yet been widely assessed in relation to previously available satellite precipitation products. Here, both IMERG V05B and V04A precipitation estimates are evaluated alongside their predecessor products (TRMM $3 \mathrm{~B} 42$ and CMORPH-CRT).

The CMORPH-CRT and TRMM $3 \mathrm{~B} 42$ precipitation estimates are both bias-corrected using a rain gauge analysis. It should also be point out that the algorithm for the TRMM 3B42 does not remain static during the whole study period. It instead switched over to the GPM satellite observations after the TRMM satellite was decommissioned in March 2015. In addition, our study period overlaps the transition between TRMM and GPM input into the TRMM 3B42 dataset. Therefore, for the time after March 2015, this study compares different retrieval algorithms, as opposed to different data sets.

The performance of the IMERG V04A algorithm in this study is consistent with earlier findings in China [13] and over the Tibetan Plateau [4]. It is interesting to note that both IMERG precipitation products do not demonstrate an advantage over their predecessor (TRMM 3B42). Compared with IMERG V04A, the IMERG V05B product shows the expected superior performance over China. Among the four satellite precipitation products, CMORPH-CRT has the worst performance over China. The IMERG products slightly improve daily POD and CSI values relative to TRMM 3B42 and CMORPH-CRT. This result may be due to the fact that the DPR of IMERG is more sensitive to light rainfall. In addition, IMERG has a shorter temporal resolution of $30 \mathrm{~min}$ which is useful in capturing short-lived precipitation events. Finally, IMERG has a finer spatial resolution $\left(0.1^{\circ}\right)$ which increases its ability to detect finescale -precipitation events.

Comparisons presented here are against 542 separate automatic meteorological stations. This is a relatively small number to evaluate the performance of satellite products 


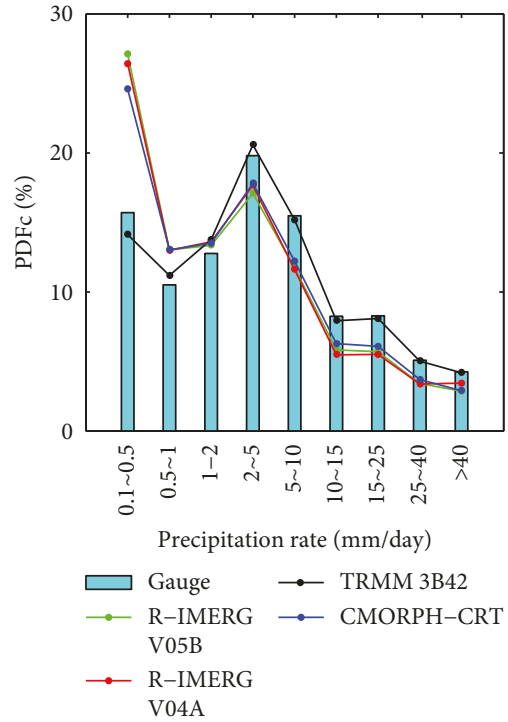

(a)

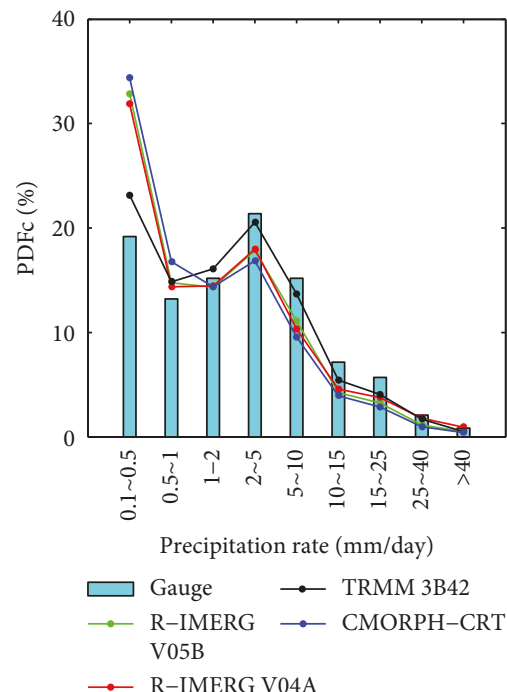

(d)

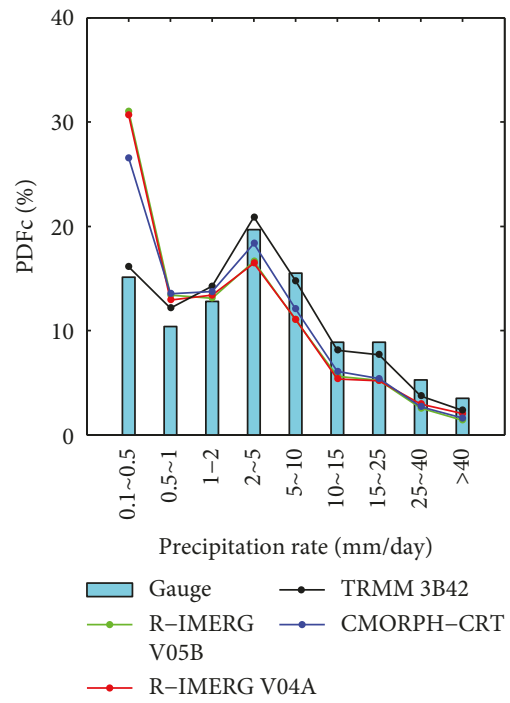

(g)

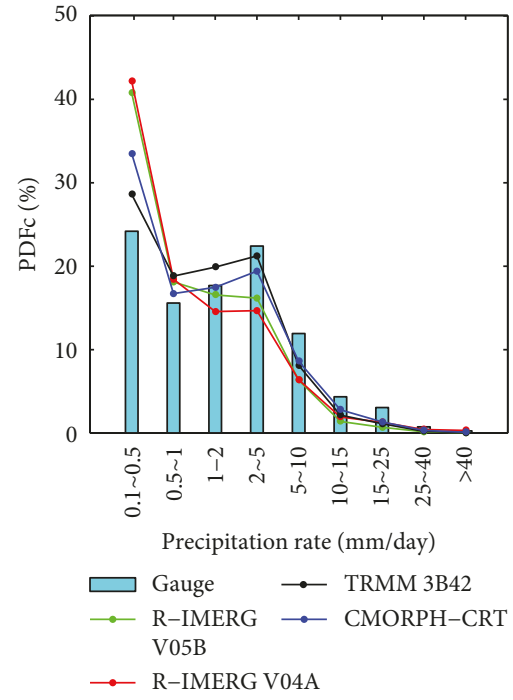

(b)

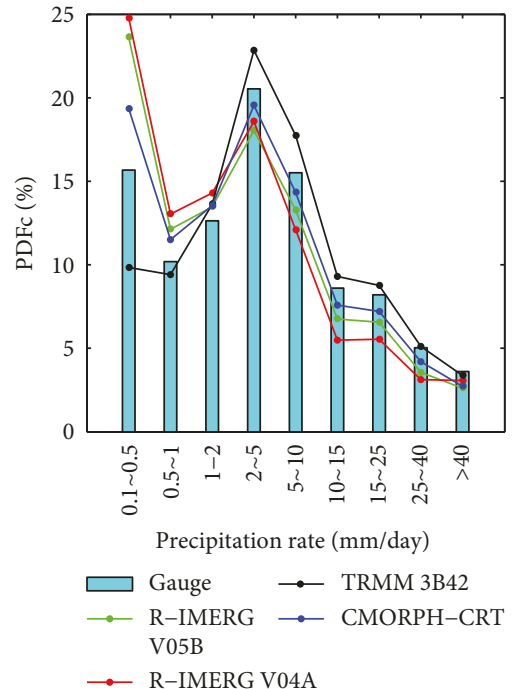

(e)

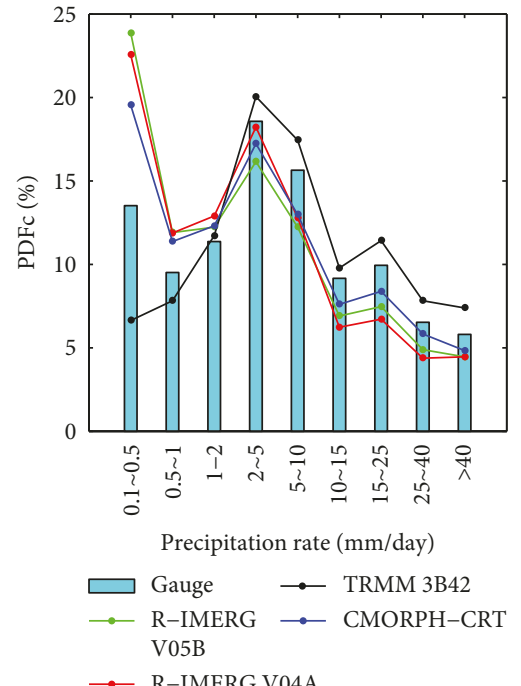

(h)

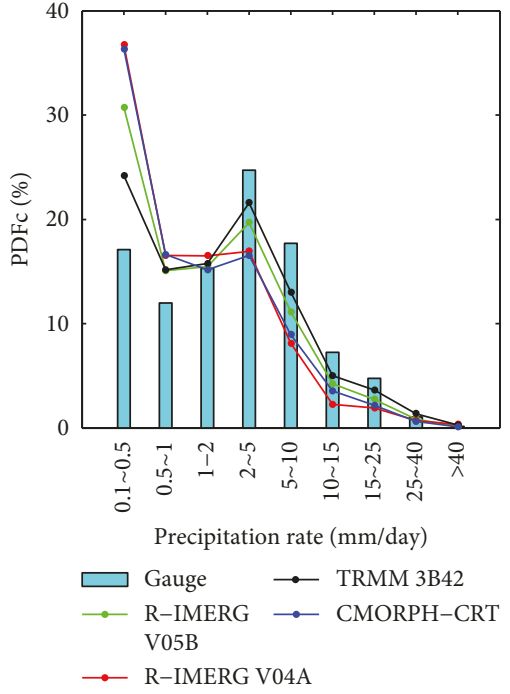

(c)

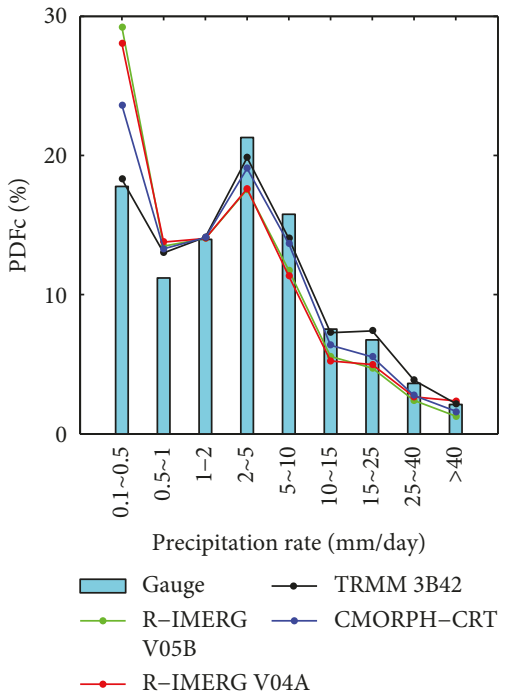

(f)

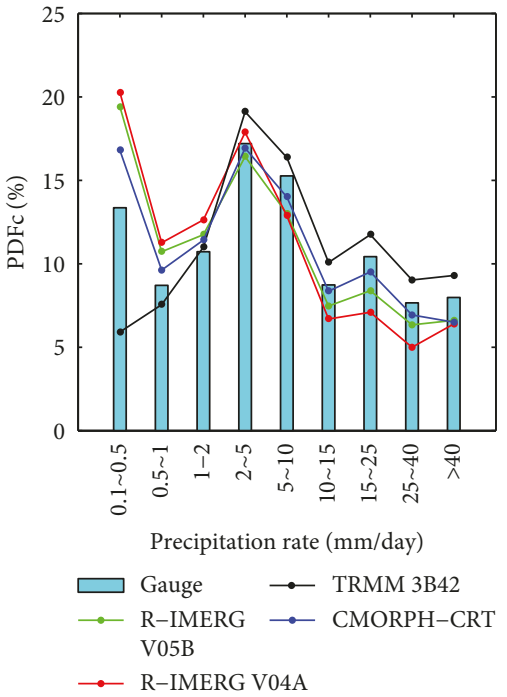

(i)

FIGURE 6: PDFc of daily precipitation during March 2014 to February 2017 for cases with different rainfall intensity bins over mainland China (a) and our eight subregions of interest: (b) XJ, (c) TP, (d) XB, (e) YG, (f) DB, (g) HB, (h) CJ, and (i) HN. (green, red, black, and blue lines present the PDFc of daily precipitation for R-IMERG V05B, R-IMERG V04A, TRMM 3B42, and CMORPH-CRT, respectively.) 


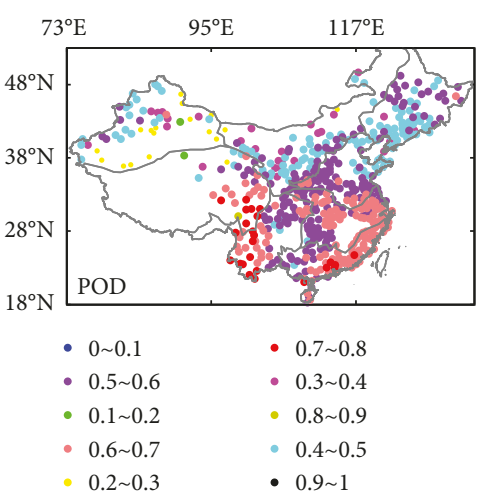

(a)

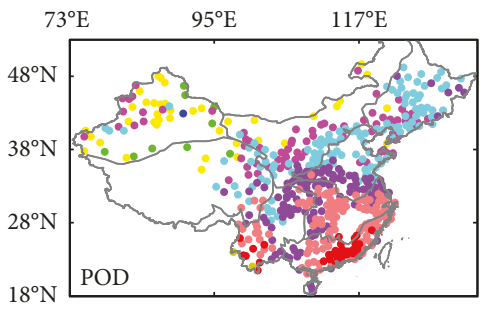

$$
\begin{aligned}
& \begin{array}{ll}
-0 \sim 0.1 & \bullet 0.7 \sim 0.8
\end{array} \\
& \text { - } 0.5 \sim 0.6 \\
& \text { - } 0.1 \sim 0.2 \\
& \text { - } 0.6 \sim 0.7 \\
& \text { - } 0.2 \sim 0.3
\end{aligned}
$$

(d)

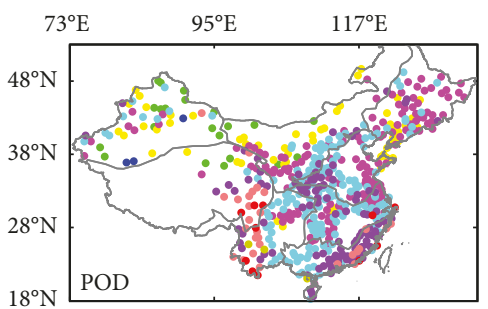

$$
\begin{aligned}
& \text { - } 0 \sim 0.1 \quad \bullet 0.7 \sim 0.8 \\
& \text { - } 0.5 \sim 0.6 \\
& \text { - } 0.1 \sim 0.2 \\
& \text { - } 0.6 \sim 0.7 \\
& \text { - } 0.2 \sim 0.3
\end{aligned}
$$

(g)

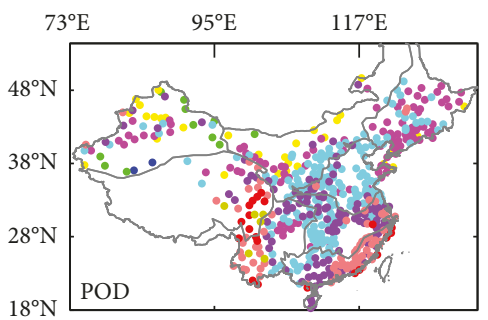

$$
\begin{aligned}
& \begin{array}{ll}
0 \sim 0.1 & \bullet 0.7 \sim 0.8
\end{array} \\
& \text { - } 0.5 \sim 0.6 \\
& \text { - } 0.1 \sim 0.2 \\
& \text { - } 0.6 \sim 0.7 \\
& \text { - } 0.2 \sim 0.3
\end{aligned}
$$

(j)

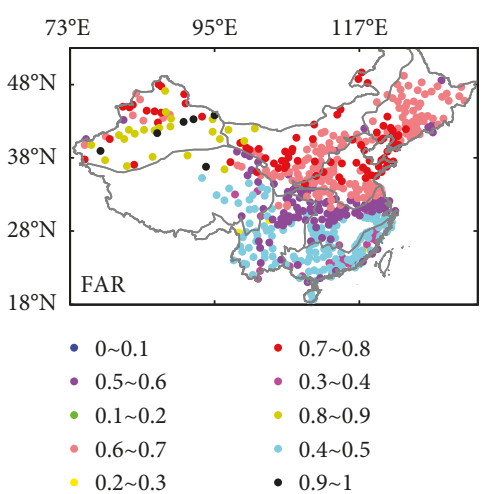

(b)

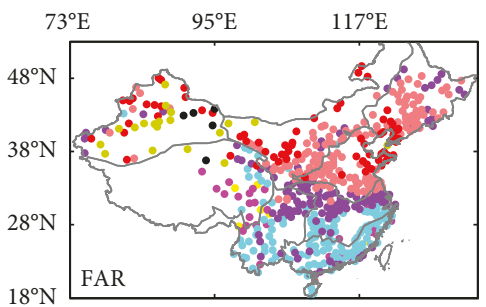

$$
\begin{aligned}
& \text { - } 0 \sim 0.1 \quad \bullet 0.7 \sim 0.8 \\
& \text { - } 0.5 \sim 0.6 \\
& \text { - } 0.1 \sim 0.2 \\
& \text { - } 0.6 \sim 0.7 \\
& \text { - } 0.2 \sim 0.3
\end{aligned}
$$

(e)

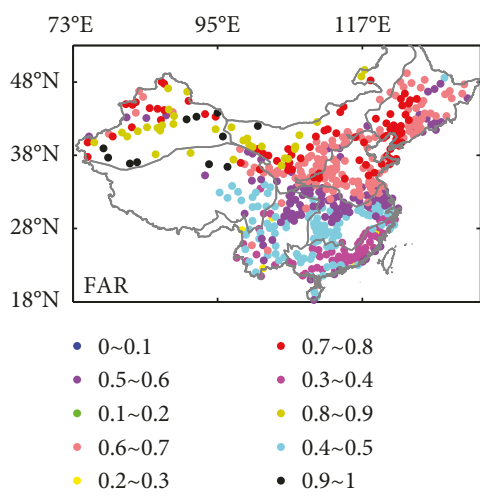

(h)

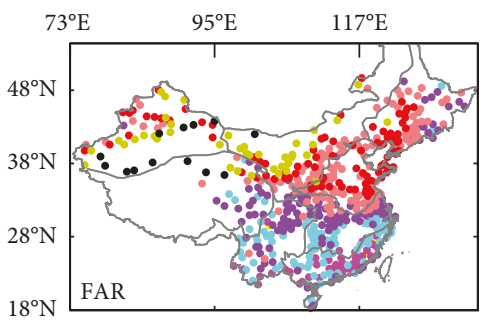

$$
\begin{aligned}
& \text { - } 0 \sim 0.1 \quad \bullet 0.7 \sim 0.8 \\
& \text { - } 0.5 \sim 0.6 \quad \text { • } 0.3 \sim 0.4 \\
& \text { - } 0.1 \sim 0.2 \quad \circ 0.8 \sim 0.9 \\
& \text { - } 0.6 \sim 0.7 \quad 0.4 \sim 0.5 \\
& \text { - } 0.2 \sim 0.3 \quad \bullet 0.9 \sim 1
\end{aligned}
$$

(k)

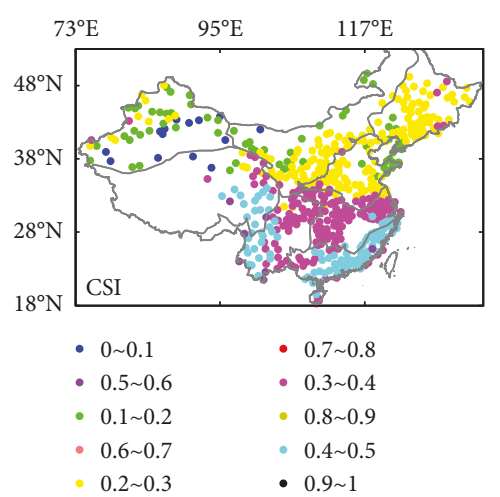

(c)

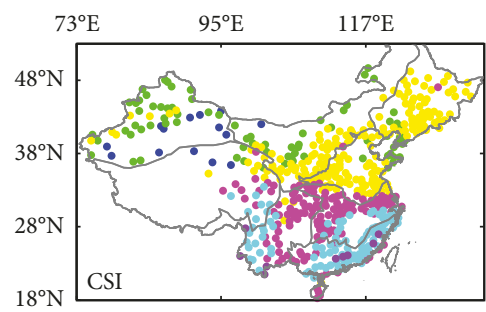

$$
\begin{aligned}
& \text { - } 0 \sim 0.1 \quad \bullet 0.7 \sim 0.8 \\
& \text { - } 0.5 \sim 0.6 \quad \cdot 0.3 \sim 0.4 \\
& \text { - } 0.1 \sim 0.2 \quad 0.8 \sim 0.9 \\
& \text { - } 0.6 \sim 0.7 \\
& \text { - } 0.4 \sim 0.5 \\
& \text { • } 0.9 \sim 1
\end{aligned}
$$

(f)

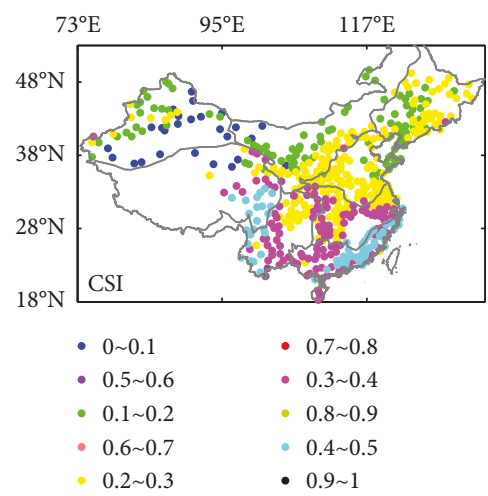

(i)

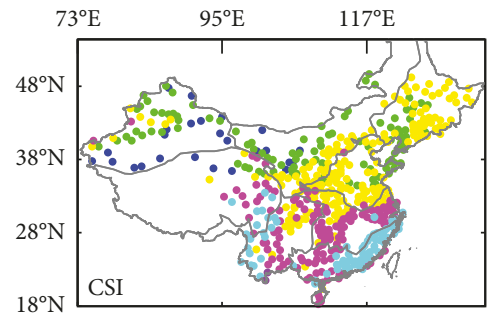
- $0 \sim 0.1$
$0.7 \sim 0.8$
- $0.5 \sim 0.6$
- $0.3 \sim 0.4$
- $0.1 \sim 0.2$
$0.6 \sim 0.7$
- $0.4 \sim 0.5$
- $0.9 \sim 1$

(l)

Figure 7: POD, FAR, and CSI performance statistics for R-IMERG V05B (a-c), R-IMERG V04A (d-f), TRMM 3B42 (g-i), and CMORPHCRT (j-1), as compared to precipitation gauges measurements acquired between March 2014 and February 2017 over Mainland China. 


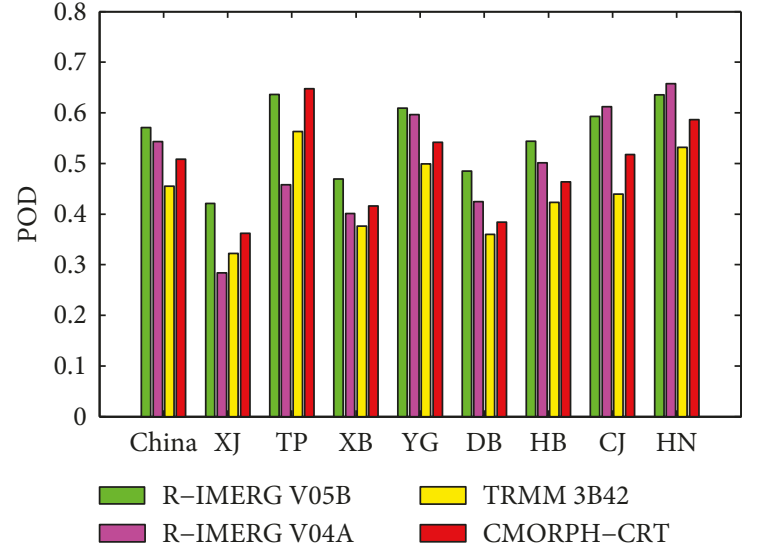

(a)

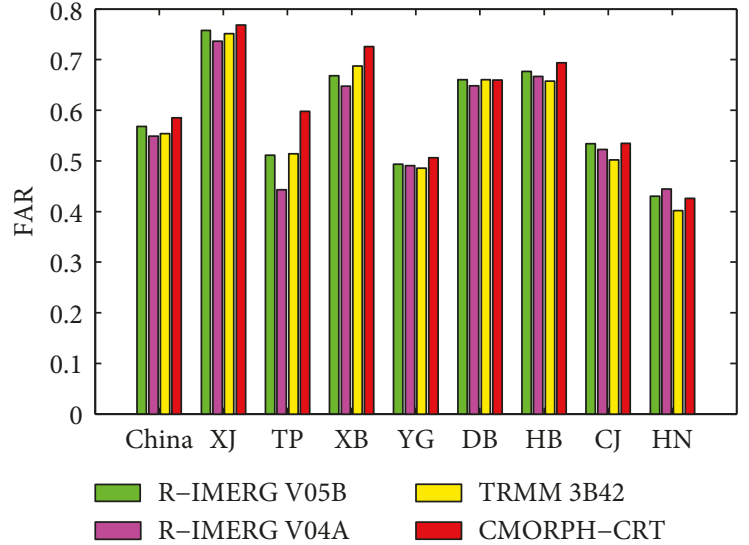

(b)

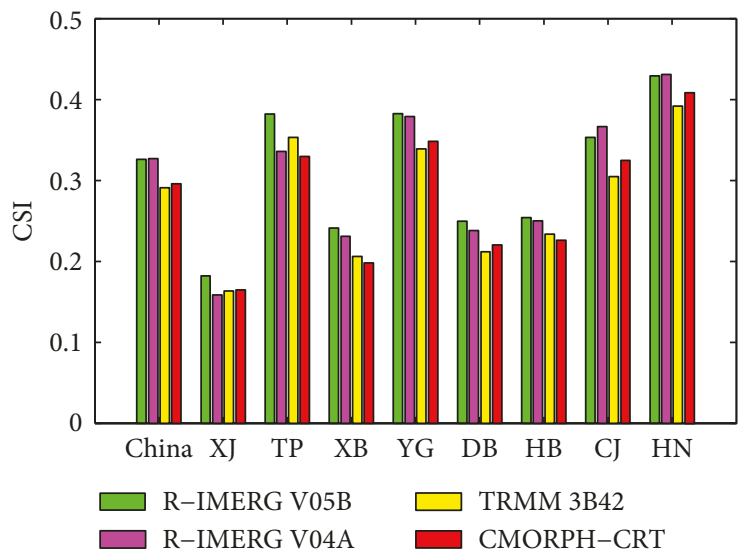

(c)

FIgURE 8: POD (a), FAR (b), and CSI (c) of daily rainfall for the R-IMERG V05B, R-IMERG V04A, TRMM 3B42, and CMORPH-CRT products compared to the precipitation gauges over Mainland China and our eight subregions between March 2014 and February 2017.

over the entire extent of mainland China. This small number also certainly increases sampling uncertainty present in our assessments. However, with IMERG equipped with dualfrequency precipitation radar, comparisons in performance of IMERG and its predecessors, TMPA and CMORPH, are necessary over highly variable climate regions across China. Furthermore, assessment of the two IMERG products is vital for further refinement of the IMERG product algorithm. Nevertheless, we should stress that additional work is needed to evaluate IMERG using more extensive ground-based measurements.

\section{Summary and Conclusion}

The IMERG algorithm incorporates the GPCC gauge analysis and a variety of precipitation observations from relevant satellite sensors to produce gridded precipitation estimates with $0.1^{\circ} \times 0.1^{\circ}$ spatial and half-hourly temporal resolution. Here, we evaluate the quality of the latest IMERG version (V05B) over all of mainland China and eight Chinese subregions. As a point of reference, IMERG V04A, CMORPH-CRT, and TRMM 3B42 precipitation estimates are also evaluated in parallel with the IMERG V05B product.
The quantitative analysis is based on comparisons with ground-based rain gauge measurements.

The main findings of this study are as follows:

(1) The IMERG V05B product does not show an advantage over its predecessor (TRMM 3B42) with respect to RB, RMSE and RRMSE results shown in Figure 3 and Table 2 over China and most of the eight subregions (except for XJ, TP, and HN) at annual scale. Over XJ, TP, and HN, IMERG V05B performs better with smaller RBs compared to TRMM 3B42; this is especially true in XJ where IMERG V05B increases $R$ from 0.69 to 0.72 , decreases RMSE from 0.3 to $0.29 \mathrm{~mm} /$ day, decreases the absolute $\mathrm{RB}$ from $7 \%$ to $5.2 \%$, and decreases RRMSE from $57.87 \%$ to 54.91 at the annual scale. Nevertheless, all the four satellite-based precipitation products are unreliable over the arid/semiarid XJ; therefore, algorithm developers should prioritize efforts to improve rainfall retrievals in arid areas. Across all of Mainland China, TRMM 3B42 has a slight advantage over the other three satellite-based precipitation products with the lowest RMSE $(0.3947 \mathrm{~mm} /$ day), RRMSE $(14.88 \%)$, and highest $R(0.9759)$ at an annual time scale. The 
other products are ranked (from best to worst) as IMERG V05B, IMERG V04A, and CMORPH-CRT.

(2) Overall, the IMERG V05B product demonstrates its expected superior performance over China with lower RMSE (0.4097 mm/day), RRMSE (15.44\%), and higher $R$ (0.9759) in Figure 3 compared with IMERG V04A in terms of a daily average precipitation analysis. Meanwhile, at the seasonal scale, IMERG V05B also has an advantage over IMERG V04A with smaller RMSEs $(0.54$ vs. $0.6 \mathrm{~mm}$ /day in spring, 0.88 vs. $0.95 \mathrm{~mm} /$ day in summer, 0.48 vs. $0.53 \mathrm{~mm} /$ day in autumn, and 0.257 vs. $0.26 \mathrm{~mm} /$ day in winter, respectively), RRMSEs (20.05\% vs. $22.15 \%$ in spring, $19 \%$ vs. $20.66 \%$ in summer, $20.1 \%$ vs. $22 \%$ in autumn, and $29.45 \%$ vs. $30.26 \%$ in winter, respectively) and higher Rs (0.979 vs. 0.973 in spring, 0.95 vs. 0.94 in autumn, and 0.95 vs. 0.94 in winter, respectively). During the spring and summer, among the four satellite-based precipitation estimates, TRMM 3B42 shows the best performance with the lowest RMSEs ( 0.53 and $0.82 \mathrm{~mm} /$ day), smallest RRMSEs (19.75\% and 17.84\%), and the highest Rs (0.981 and 0.96). However, CMORPH-CRT has the worst performance with largest RMSEs, RRMSEs, and the lowest Rs in every season.

(3) During annual daily average precipitation analysis, IMERG V04A severely underestimates average precipitation in western parts of China (XJ and TP); however, IMERG V05B demonstrates better RB performance than IMERG V04A (5.2\% vs. $-21.8 \%$ over XJ, $2.78 \%$ vs. $-46 \%$ over $\mathrm{TP}$, respectively). Compared with IMERG V05B and TRMM 3B42, IMERG V04A shows a comparable level of precipitation underestimation over XJ with a lower RB of $-31.41 \%(-34.01 \%,-77.79 \%)$ based on the spring (autumn, winter) daily mean precipitation and an even worse performance over TP with a much lower $\mathrm{RB}$ of $-69.78 \%(-33.99 \%,-52.7 \%$, and $-89.63 \%)$ based on spring (summer, autumn, and winter) daily average precipitation. In contrast, CMORPH-CRT overestimates precipitation over $\mathrm{XJ}$ in terms of annual-scale RB (21.9\%).

(4) All the four satellite-based precipitation estimates show a distinct overestimation based on calculated RBs in Table 2 over XB, YG, DB, HB, CJ, and HN (except for CMORPH-CRT over HN). For example, IMERG V05B overestimates precipitation with a RB of $8.71 \%$ (15.6\% and $10.57 \%)$ over XB (DB and HB). Over these three subregions, all RBs of the other three satellite-based precipitation estimates are lower than the corresponding RBs for IMERG V05B, especially CMORPH-CRT improves the overestimation with RBs down to $0.7 \%$ over $\mathrm{DB}$ and $4.36 \%$ over $\mathrm{HB}$, respectively. According to RBs listed in Table 3, compared with IMERG V05B, all the three satellite-based precipitation estimates have lower $\mathrm{RBs}$ over $\mathrm{XB}, \mathrm{DB}$, and $\mathrm{HB}$ during both the spring and autumn.
(5) Over all of Mainland China, across all four seasons, the four satellite-based precipitation products all exhibit their largest RRMSEs (Figure 5) during winter. Similar results are seen over all eight subregions except for CMORPH-CRT over XJ. Therefore, in general, satellite-based precipitation estimates perform worse during winter relative to other seasons.

(6) Judging by PDFc results, both IMERG products and CMORPH-CRT overestimate the frequency of light precipitation (less than $1 \mathrm{~mm} /$ day) and show a slight underestimation for rain rate bins greater than $2 \mathrm{~mm} /$ day over all of mainland China and in each of the our eight subregions. In general, among the four satellite precipitation products, TRMM 3B42 agrees best with PDFc results obtained from rain gauges.

(7) All four satellite-based precipitation products demonstrate low POD $(<0.66)$ and CSI $(<0.44)$ scores and high value of of FAR $(>0.4)$ over China and within each of our eight subregions. However, both IMERG products have better scores of POD and CSI than the other two satellite precipitation products over China and across most of the subregions except for IMERG V04A over XJ, TP, and XB (Figure 8).

(8) IMERG eliminates anomalous values of TRMM 3B42 and CMORPH-CRT found in isolated grid boxes. This is likely due to the higher spatiotemporal resolution $\left(30 \mathrm{~min} / 0.1^{\circ}\right)$ of IMERG products.

This analysis provides important insight regarding the spatiotemporal error characteristics of the IMERG V05B, IMERG V04A, CMORPH-CRT, and TRMM 3B42 precipitation products over China and the eight subregions examined here. As such, these results provide satellite precipitation users with an enhanced understanding of the applicability of the latest V05 IMERG, V04 IMERG, TRMM 3B42, and CMORPH-CRT precipitation estimates for water resource management, hydrometeorological disaster prediction, and hydrologic simulation within China. In addition, results are potentially relevant for future refinement of the IMERG production algorithm.

\section{Data Availability}

The data used to support the findings of this study are available from the corresponding author upon request.

\section{Conflicts of Interest}

The authors declare no conflicts of interest.

\section{Authors' Contributions}

All authors contributed extensively to the work presented in this paper. Haishen Lu, Wade T. Crow, and Yonghua Zhu designed the framework of this study. Guanghua Wei performed the experiment. The manuscript was prepared by Guanghua Wei and revised by Haishen Lu, Wade T. Crow, and Yonghua Zhu. The data were provided by Guanghua 
Wei and Jianbin Su. Jianqun Wang provided some useful suggestions.

\section{Acknowledgments}

This research is supported by National Key Research and Development Program (grant nos. 2016YFC0400909 and 2016YFA0601504); NNSF (grant nos. 41830752 and 41571015, 41371049, 41323001, and 51539003); and the Project of the State Key Laboratory of Hydrology-Water Resources and Hydraulic Engineering, China (grant nos. 20165042612).

\section{References}

[1] A. Y. Hou, R. K. Kakar, S. Neeck et al., "The global precipitation measurement mission," Bulletin of the American Meteorological Society, vol. 95, pp. 701-722, 2014.

[2] H. Lü, W. Crow, Y. Zhu, F. Ouyang, and J. Su, "Improving streamflow prediction using remotely-sensed soil moisture and snow depth," Remote Sensing, vol. 8, no. 6, p. 503, 2016.

[3] J. Su, H. Lü, J. Wang, A. M. Sadeghi, and Z. Yonghua, "Evaluating the applicability of four latest satellite gauge combined precipitation estimates for extreme precipitation and streamflow predictions over the upper yellow river basins in China," Remote Sensing, vol. 9, no. 11, p. 1176, 2017.

[4] G. Wei, H. Lü, W. T. Crow, Y. Zhu, J. Wang, and J. Su, "Evaluation of satellite-based precipitation products from IMERG V04A and V03D, CMORPH and TMPA with gauged rainfall in three climatologic zones in China," Remote Sensing, vol. 10, no. 2, p. 30, 2017.

[5] J. Hu, X. Liu, L. Liu, and L. Guan, "Evaluating the performance of the scope model in simulating canopy solar-induced chlorophyll fluorescence," Remote Sensing, vol. 10, no. 2, p. 250, 2018.

[6] M. N. Anjum, Y. Ding, D. Shangguan et al., "Performance evaluation of latest integrated multi-satellite retrievals for global precipitation measurement (IMERG) over the northern highlands of Pakistan," Atmospheric Research, vol. 205, pp. 134-146, 2018.

[7] E. Omranian and H. O. Sharif, "Evaluation of the global precipitation measurement (GPM) satellite rainfall products over the lower Colorado river basin, Texas," JAWRA Journal of the American Water Resources Association, vol. 54, no. 4, pp. 882-898, 2018.

[8] E. Sharifi, R. Steinacker, and B. Saghafian, "Multi time-scale evaluation of high-resolution satellite-based precipitation products over northeast of Austria," Atmospheric Research, vol. 206, pp. 46-63, 2018.

[9] A. S. Gebregiorgis, P. E. Kirstetter, Y. E. Hong et al., "To what extent is the day 1 GPM IMERG satellite precipitation estimate improved as compared to TRMM TMPA-rt?," Journal of Geophysical Research: Atmospheres, vol. 123, 2018.

[10] J. Su, H. Lü, Y. Zhu, X. Wang, and G. Wei, "Component analysis of errors in four GPM-based precipitation estimations over Mainland China," Remote Sensing, vol. 10, no. 9, p. 1420,2018

[11] H. Zhao, B. Yang, S. Yang et al., "Systematical estimation of GPM-based global satellite mapping of precipitation products over China," Atmospheric Research, vol. 201, pp. 206-217, 2018.

[12] P. Xie and P. A. Arkin, "An intercomparison of gauge observations and satellite estimates of monthly precipitation,"
Journal of Applied Meteorology, vol. 34, no. 5, pp. 1143-1160, 1995.

[13] H. Zhao, S. Yang, S. You, Y. Huang, Q. Wang, and Q. Zhou, "Comprehensive evaluation of two successive v3 and v4 IMERG final run precipitation products over mainland China," Remote Sensing, vol. 10, no. 2, p. 34, 2017.

[14] R. J. Joyce, J. E. Janowiak, P. A. Arkin, and P. Xie, "CMORPH: a method that produces global precipitation estimates from passive microwave and infrared data at high spatial and temporal resolution," Journal of Hydrometeorology, vol. 5, no. 3, pp. 287-296, 2004.

[15] G. J. Huffman, D. T. Bolvin, E. J. Nelkin et al., "The TRMM multisatellite precipitation analysis (TMPA): quasi-global, multiyear, combined-sensor precipitation estimates at fine scales," Journal of Hydrometeorology, vol. 8, no. 1, pp. 237247, 2007.

[16] G. J. Huffman, D. T. Bolvin, D. Braithwaite et al., Algorithm Theoretical Basis Document (ATBD) Version 4.5: Nasa Global Precipitation Measurement (GPM) Integrated Multi-Satellite Retrievals for GPM (IMERG), NASA/GSFC, Greenbelt, MD, USA, 2015.

[17] Y. Shen, P. Zhao, Y. Pan, and J. Yu, "A high spatiotemporal gauge-satellite merged precipitation analysis over China," Journal of Geophysical Research: Atmospheres, vol. 119, no. 6, pp. 3063-3075, 2014.

[18] Y. Shen, A. Xiong, Y. Wang, and P. Xie, "Performance of highresolution satellite precipitation products over China," Journal of Geophysical Research, vol. 115, pp. 355-365, 2010.

[19] Q. Hu, D. Yang, Z. Li, A. K. Mishra, Y. Wang, and H. Yang, "Multi-scale evaluation of six high-resolution satellite monthly rainfall estimates over a humid region in China with dense rain gauges," International Journal of Remote Sensing, vol. 35, no. 4, pp. 1272-1294, 2014.

[20] J. Liu, Z. Duan, J. Jiang, and A. X. Zhu, "Evaluation of three satellite precipitation products TRMM 3B42, CMORPH, and PERSIANN over a subtropical watershed in China," Advances in Meteorology, vol. 2015, Article ID 151239, 13 pages, 2015.

[21] H. Guo, S. Chen, A. Bao, J. Hu, B. Yang, and P. Stepanian, "Comprehensive evaluation of high-resolution satellite-based precipitation products over China," Atmosphere, vol. 7, no. 1, p. 6, 2015.

[22] J. Kim, I. Jung, K. Park, S. Yoon, and D. Lee, "Hydrological utility and uncertainty of multi-satellite precipitation products in the mountainous region of South Korea," Remote Sensing, vol. 8, no. 7, p. 608, 2016.

[23] B. Yong, Y. Hong, L. L. Ren et al., "Assessment of evolving TRMM-based multisatellite real-time precipitation estimation methods and their impacts on hydrologic prediction in a high latitude basin," Journal of Geophysical Research: Atmospheres, vol. 117, no. 9, article D09108, 2013.

[24] Z. Zulkafli, W. Buytaert, C. Onof et al., "A comparative performance analysis of TRMM 3b42 (TMPA) versions 6 and 7 for hydrological applications over andean-amazon river basins," Journal of Hydrometeorology, vol. 15, no. 2, pp. 581-592, 2014.

[25] A. Behrangi, K. Andreadis, J. B. Fisher et al., "Satellite-based precipitation estimation and its application for streamflow prediction over mountainous western U.S. basins," Journal of Applied Meteorology and Climatology, vol. 53, no. 12, pp. 2823-2842, 2014.

[26] B. Yong, L. L. Ren, Y. Hong et al., "Hydrologic evaluation of multisatellite precipitation analysis standard precipitation products in basins beyond its inclined latitude band: a case 
study in Laohahe basin, China," Water Resources Research, vol. 46, no. 7, pp. 759-768, 2010.

[27] Y. Qin, Z. Chen, Y. Shen, S. Zhang, and R. Shi, "Evaluation of satellite rainfall estimates over the Chinese mainland," Remote Sensing, vol. 6, no. 11, pp. 11649-11672, 2014.

[28] S. Chen, Y. Hong, J. J. Gourley et al., "Evaluation of the successive v6 and v7 TRMM multisatellite precipitation analysis over the continental United States," Water Resources Research, vol. 49, no. 12, pp. 8174-8186, 2013.

[29] S. Gebere, T. Alamirew, B. Merkel, and A. Melesse, "Performance of high resolution satellite rainfall products over data scarce parts of eastern Ethiopia," Remote Sensing, vol. 7, no. 9, pp. 11639-11663, 2015.

[30] G. J. Huffman, D. T. Bolvin, and E. J. Nelkin, Day 1 IMERG Final Run Release Notes, NASA/GSFC, Greenbelt, MD, USA, 2015.

[31] S. Prakash, A. K. Mitra, D. S. Pai, and A. Aghakouchak, "From TRMM to GPM: how well can heavy rainfall be detected from space?," Advances in Water Resources, vol. 88, pp. 1-7, 2015.

[32] S. Prakash, A. K. Mitra, A. Aghakouchak, Z. Liu, H. Norouzi, and D. S. Pai, "A preliminary assessment of GPM-based multi-satellite precipitation estimates over a monsoon dominated region," Journal of Hydrology, vol. 565, pp. 865876, 2016.

[33] M. L. Tan and Z. Duan, "Assessment of GPM and TRMM precipitation products over Singapore," Remote Sensing, vol. 9, no. 7, p. 720, 2017.

[34] M. L. Tan and H. Santo, "Comparison of GPM IMERG, TMPA 3B42 and PERSIANN-CDR satellite precipitation products over Malaysia," Atmospheric Research, vol. 202, pp. 63-76, 2017.

[35] F. Yuan, L. Zhang, K. Win et al., "Assessment of GPM and TRMM multi-satellite precipitation products in streamflow simulations in a data-sparse mountainous watershed in Myanmar," Remote Sensing, vol. 9, no. 3, p. 302, 2017.

[36] W. Wang, H. Lu, T. Zhao, L. Jiang, and J. Shi, "Evaluation and comparison of daily rainfall from latest GPM and TRMM products over the mekong river basin," IEEE Journal of Selected Topics in Applied Earth Observations and Remote Sensing, vol. 10, no. 6, pp. 2540-2549, 2017.

[37] F. Chen and X. Li, "Evaluation of IMERG and TRMM 3B43 monthly precipitation products over mainland China," Remote Sensing, vol. 8, no. 6, p. 472, 2016.

[38] H. Guo, S. Chen, A. Bao et al., "Early assessment of integrated multi-satellite retrievals for global precipitation measurement over China," Atmospheric Research, vol. 176-177, pp. 121-133, 2016.

[39] G. Tang, Y. Ma, D. Long, L. Zhong, and Y. Hong, "Evaluation of GPM day-1 IMERG and TMPA version-7 legacy products over mainland China at multiple spatiotemporal scales," Journal of Hydrology, vol. 533, pp. 152-167, 2016.

[40] G. J. Huffman, E. J. Nelkin, E. F. Stocker, and J. Tan, V05 IMERG Final Run Release Notes, NASA/GSFC, Greenbelt, MD, USA, 2017.

[41] T. Zhou, D. Gong, J. Li, and B. Li, "Detecting and understanding the multi-decadal variability of the east asian summer monsoon-recent progress and state of affairs," Meteorologische Zeitschrift, vol. 18, no. 4, pp. 455-467, 2009.

[42] S. Chen, Y. Hong, Q. Cao et al., "Similarity and difference of the two successive v6 and v7 TRMM multisatellite precipitation analysis performance over China," Journal of Geophysical Research: Atmospheres, vol. 118, no. 23, pp. 13060-13074, 2013.
[43] R. Yu, T. Zhou, A. Xiong, Y. Zhu, and J. Li, "Diurnal variations of summer precipitation over contiguous China," Geophysical Research Letters, vol. 34, no. 1, pp. 223-234, 2007.

[44] R. J. Joyce, P. Xie, Y. Yarosh, J. E. Janowiak, and P. A Arkin, "CMORPH: a "morphing" approach for high resolution precipitation product generation," in Satellite Rainfall Applications for Surface Hydrology, M. Gebremichael and F. Hossain, Eds., pp. 23-37, Springer, Netherlands, 2010.

[45] E. Habib, A. T. Haile, Y. Tian, and R. J. Joyce, "Evaluation of the high-resolution CMORPH satellite rainfall product using dense rain gauge observations and radar-based estimates," Journal of Hydrometeorology, vol. 13, no. 6, pp. 1784-1798, 2012.

[46] G. J. Huffman, D. T. Bolvin, E. J. Nelkin, and E. F. Stocker, V04 IMERG Final Run Release Notes, NASA/GSFC, Greenbelt, MD, USA, 2017.

[47] B. Ahrens, "Distance in spatial interpolation of daily rain gauge data," Hydrology and Earth System Sciences, vol. 10, no. 2, pp. 197-208, 2006.

[48] K. Tong, F. Su, D. Yang, L. Zhang, and Z. Hao, “Tibetan plateau precipitation as depicted by gauge observations, reanalyses and satellite retrievals," International Journal of Climatology, vol. 34, no. 2, pp. 265-285, 2014.

[49] Z. Liu, "Comparison of integrated multisatellite retrievals for GPM (IMERG) and TRMM multisatellite precipitation analysis (TMPA) monthly precipitation products: initial results," Journal of Hydrometeorology, vol. 17, no. 3, pp. 777790, 2015.

[50] E. Sharifi, R. Steinacker, and B. Saghafian, "Assessment of GPM-IMERG and other precipitation products against gauge data under different topographic and climatic conditions in Iran: preliminary results," Remote Sensing, vol. 8, no. 2, p. 135, 2016.

[51] M. S. Al-Musaylh, R. C. Deo, Y. Li, and J. F. Adamowski, "Two-phase particle swarm optimized-support vector regression hybrid model integrated with improved empirical mode decomposition with adaptive noise for multiplehorizon electricity demand forecasting," Applied Energy, vol. 217, pp. 422-439, 2018.

[52] F. Ehrhardt, J. F. Soussana, G. Bellocchi et al., "Assessing uncertainties in crop and pasture ensemble model simulations of productivity and $\mathrm{N}_{2} \mathrm{O}$ emissions," Global Change Biology, vol. 24, no. 2, pp. e603-e616, 2018.

[53] H. Ren, G. Zhou, and F. Zhang, "Using negative soil adjustment factor in soil-adjusted vegetation index (savi) for aboveground living biomass estimation in arid grasslands," Remote Sensing of Environment, vol. 209, pp. 439-445, 2018.

[54] S. Ning, F. Song, P. Udmale, J. Jin, B. R. Thapa, and H. Ishidaira, "Error analysis and evaluation of the latest GSMAP and IMERG precipitation products over eastern China," Advances in Meteorology, vol. 2017, Article ID 1803492, 16 pages, 2017.

[55] Y. Tian, C. D. Peters-Lidard, B. J. Choudhury, and M. Garcia, "Multitemporal analysis of TRMM-based satellite precipitation products for land data assimilation applications," Journal of Hydrometeorology, vol. 8, no. 6, pp. 1165-1183, 2007. 

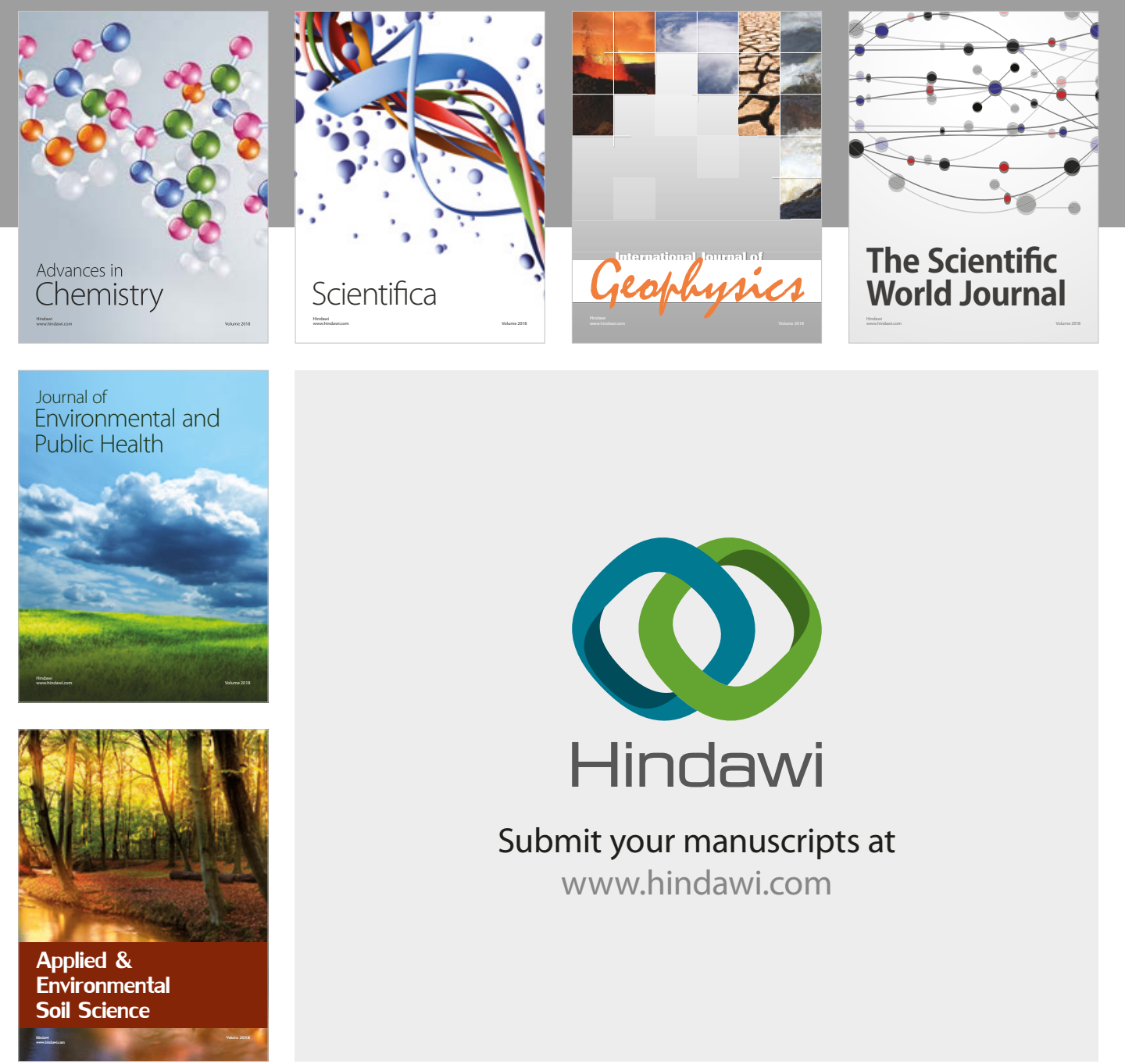

The Scientific

\section{World Journal}
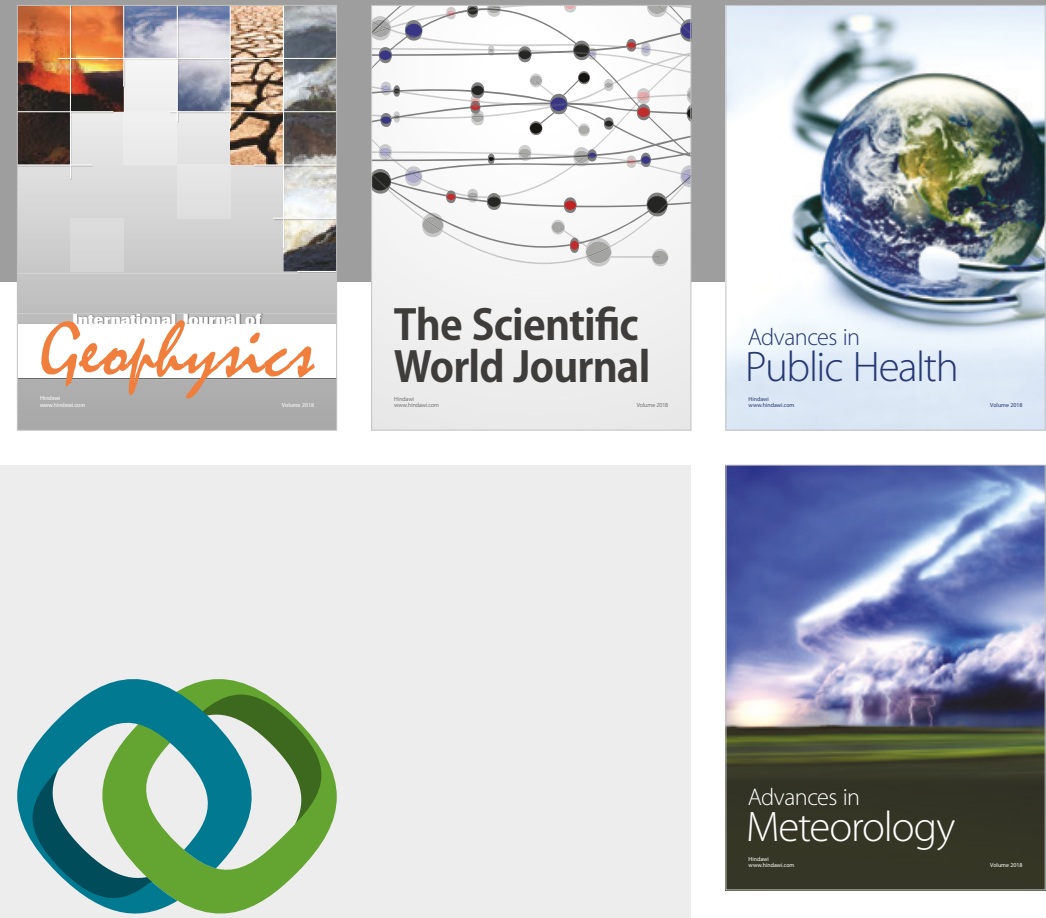

Advan

Public Health

\section{Hindawi}

Submit your manuscripts at

www.hindawi.com
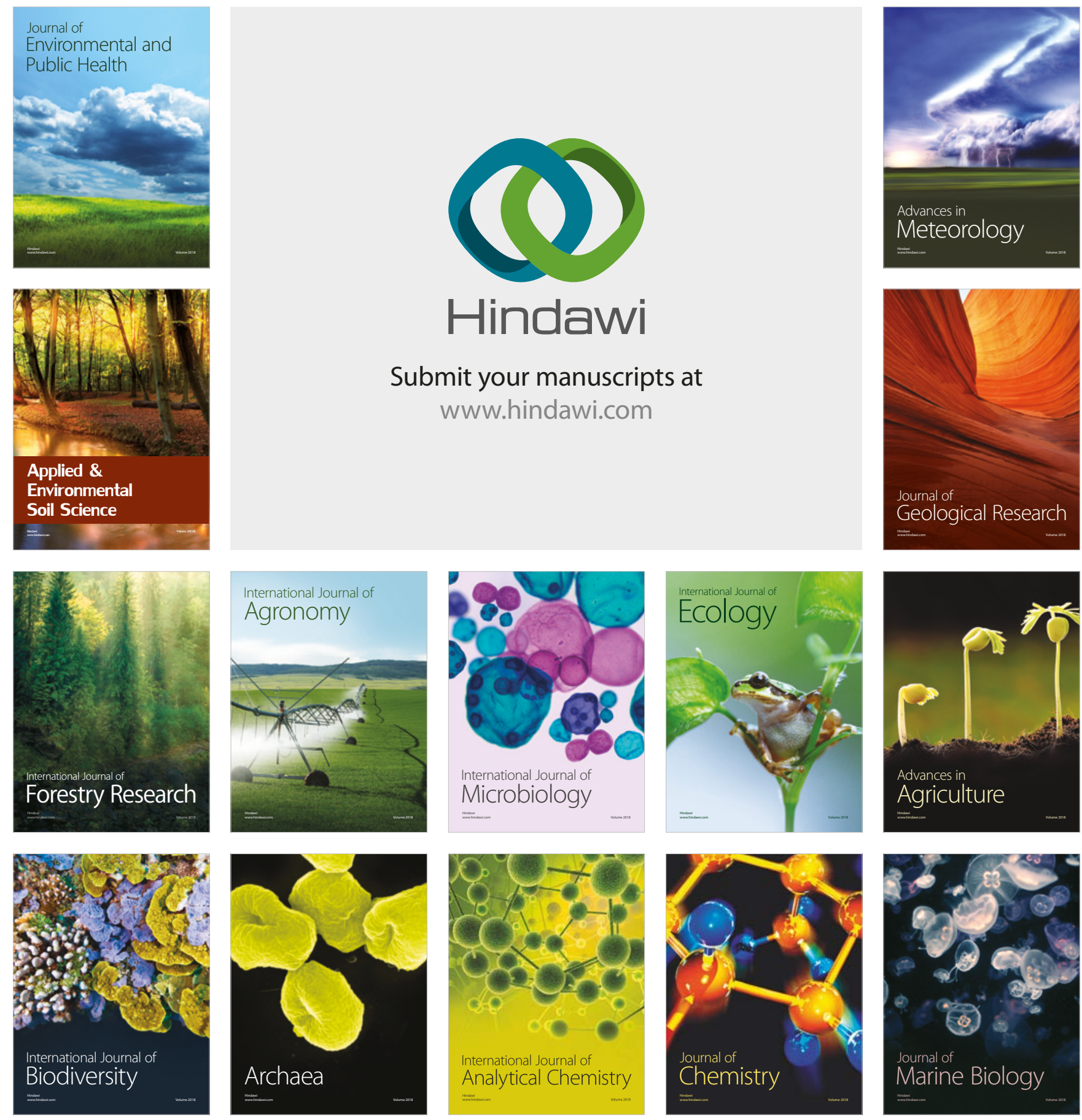